\title{
Renewable responsive systems based on original click and polyurethane crosslinked architectures with advanced properties
}

Khantutta-Kim Tremblay-Parrado[a], Luc Avérous ${ }^{[a]}$

[a]BioTeam/ICPEES-ECPM, UMR CNRS 7515, Université de Strasbourg, 25 rue Becquerel, 67087 Strasbourg, Cedex 2, France

* Corresponding author: Prof. Luc Avérous, Phone: + 333 68852784, Fax: + 333 68852716, E-mail: luc.averous@unistra.fr

\section{Abstract:}

A new chemical architecture from oleic acid consisting of a diol structure containing pendent furan rings denoted the Furan Oligomer (FO) was synthesized and fully characterized. The FO was integrated into a linear rapeseed-based polyurethane (PU) backbone and crosslinked via DielsAlder (DA) reaction using the pendent furan rings and a short polypropylene oxide based bismaleimide. This is the first time a thermo-reversible PU network based on vegetable oil is reported. The effects of varying proportions of FO in linear and crosslinked systems, by DA, were studied. These materials were analyzed by classic characterization techniques. The stability and recyclability of the crosslinked materials were shown by successive reprocessing cycles and reanalyzing the mechanical properties. Self-healing properties were macroscopically exhibited

Renewable Resources, Oleic acid, Biobased polymers, Polyurethane, Diels-Alder Cycloaddition

\section{Keywords:} and by tensile tests of healed materials. The resulting crosslinked materials present a large range of properties such as tunable mechanical and thermo-responsive behavior, good thermal recyclability and self-healing abilities. 


\section{Table of Content}

2 Khantutta-Kim Tremblay-Parrado, Pr. Luc Avérous

4 Renewable responsive systems based on original click and polyurethane crosslinked 5 architectures with advanced properties

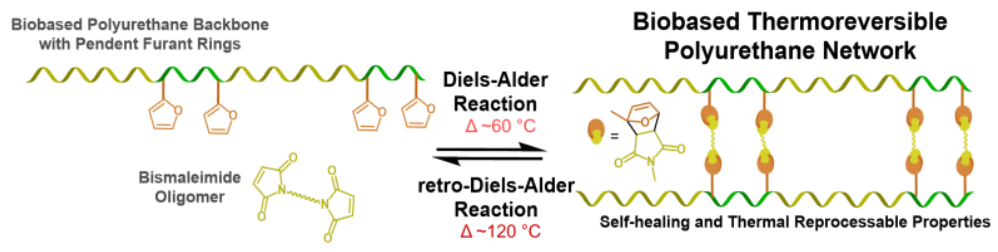

7 Biobased Thermo-reversible Polyurethane: A new architecture from oleic acid consisting 8 pendent furan rings denoted the Furan Oligomer (FO) was synthesized. The FO was integrated 9 into a linear biobased polyurethane backbone and crosslinked via Diels-Alder reaction using a 10 bismaleimide oligomer. The resulting networks present interesting properties such as tunable 11 mechanical and thermos-responsive behavior, recyclability and a self-healing ability. 


\section{Introduction}

2 Nowadays, developing biobased and environmentally friendly materials is not enough. Science

3 has to face developing advanced materials with extending lifetimes and with a controlled end of

4 life. Polymer materials with innovative architectures allowing for cutting-edge properties such as

5 self-healing and reprocessability, do not only extend the life of end-user materials, but also allow

6 for the reduction of energy use, resources and waste. Polyurethanes (PUs) are of particular

7 interest to integrate these novel properties due to their global versatility. PUs are used for a wide

8 range of applications such as adhesives, coatings, automotive and construction industry. ${ }^{[1]}$ Their

9 production is ranked $6^{\text {th }}$ amongst all polymers, ${ }^{[2]}$ with a planned production of approximately 23 10 million tons in 2019. ${ }^{[3]}$ Although the biobased PU market is expanding, limited work has explored 11 the development biobased PUs with particular architectures to allow for dynamic and adaptable 12 materials. Developing biobased materials and PUs is a starting point to a circular economy but by designing biobased PUs with dynamic architectures, this truly takes in to account the cradle-tograve reasoning of materials to facilitate recyclability and the extension of material lifetime.

To develop renewable materials, vegetable oils have a particular importance, as they are abundantly available at rather low costs with attractive chemical structures for a rich chemistry. ${ }^{[4]}$ Soybean oil is the most abundantly produced vegetable oil and it is has been particularly explored by academics and industrials for PU thermoset applications..$^{[4-5]}$ Studies reporting the use of vegetable oils to synthesize diols for linear thermoplastic PUs (TPUs) include (i) the use of methyl oleate and ricinoleic acid through transesterification, epoxidation, ring-opening of epoxides and thiol-ene addition, ${ }^{[6]}$ (ii) methyl ester of rapeseed oil through transesterification and thiol-ene coupling, ${ }^{[7]}$ (iii) polyricinoleate diol by polycondensation ${ }^{[8]}$ and (iv) the dimerization of rapeseed oil fatty acids at high temperature by a Diels-Alder (DA) mechanism. ${ }^{[9]}$ Consequently, the use of vegetable oils for the development of biobased PUs is a favorable starting point. Nevertheless, there is an apparent lack, particularly at the industrial level, in the development of advanced biobased PUs materials with dynamic architectures for a well-thought out reflection of the extension of polymer material lifetimes.

In order to extend the lifetime of polymers, many efforts have been made to develop dynamic and reversible polymers. Such a behavior is based on the development of dynamic covalent bonds that can be formed and cleaved by exposure to an external stimulus or autonomously. Crosslinked polymers containing reversible covalent bonds are defined as Covalent Adaptive Networks (CANs) ${ }^{[10]}$ and can be further subdivide in two categories ${ }^{[11]}$, dissociative and associative systems. 
Associative CANs consists of bond exchange between polymer chains, where the overall crosslinking density is preserved as a new covalent bond can only be formed if another has been broken, such as vitrimers, ${ }^{[12]}$ which can also be biobased. ${ }^{[13]}$ Dissociative CANs consist of chemical bond exchanges where bonds are first broken and then formed again in another place. Reversible covalent bonds such as the $\mathrm{DA}^{[14]}$ reaction or alkoxyamine ${ }^{[15]}$ chemistry can be used. As highlighted by the work of Gandini and co-workers, the thermoreversible furan-maleimide [4+2] cycloaddition DA reaction is the most extensively studied reversible covalent bond of dissociative CANs used in the synthesis of macromolecular architectures. ${ }^{[16]}$ The DA reaction between a furan and maleimide moiety is considered as a cycloaddition "click" reaction, generally occurring at moderate temperature (below $90^{\circ} \mathrm{C}$ ) and the reversion reaction denoted as the retro-DA ( $\mathrm{r}$-DA) reaction, occurs between 110 and $130{ }^{\circ} \mathrm{C} \cdot{ }^{[17]}$ The reactivity and reversibility of the DA and r-DA reactions can be tuned significantly depending on the substituents located on a furan and maleimide moiety. ${ }^{[18]}$ Several biobased CANs have been synthesized using the thermoreversible DA reaction derived from lignins ${ }^{[19]}$, tannins ${ }^{[20]}$, alginate ${ }^{[21]}$, chitosan ${ }^{[22]}, \operatorname{starch}^{[23]}$ or vegetable oils. ${ }^{[16 a]}$

Using the DA reaction in PUs is of particular interest as it is believed that the shape memory behavior of PUs facilitates the self-healing by DA reaction. ${ }^{[24]}$ Consequently, reversibly crosslinked PUs have been studied through a multitude of different strategies. ${ }^{[25]}$ Nevertheless, only very few studies explore the use of biobased PUs as a canvas to investigate reversibly crosslinked polymers. Gu et al. synthesized a biobased TPU backbone using a renewable polylactide copolymer diol and 2,5-furandimethanol as a soft segment and chain extender respectively. The reversible covalent bonds were located in the hard segments (HS) where the DA reaction took place between the furan ring of the chain extender and a bismaleimide. ${ }^{[26]}$ Wilson et al. synthesized an original $\mathrm{C}_{11}$ difuranic diol from furfural and 5-hydroxymethylfurufral, which they used to synthesize polyesters and reversibly crosslinked polyurethanes networks with a bismaleimide. ${ }^{[27]}$

In the present work, we produced reversibly crosslinked PUs based on vegetable oils using thermally reversible furan-maleimide DA reaction. We synthesized a new chemical architecture from oleic acid, consisting of a diol structure, containing pendent furan rings, which was thoroughly characterized and denoted as the Furan Oligomer (FO). As depicted in Scheme 1, FO was incorporated into the linear polymer backbone and further crosslinked with the use of a bismaleimide based on polypropylene oxide (PPO BMI). The corresponding materials with varying crosslinking contents were tested as remendable and self-healing PUs. 


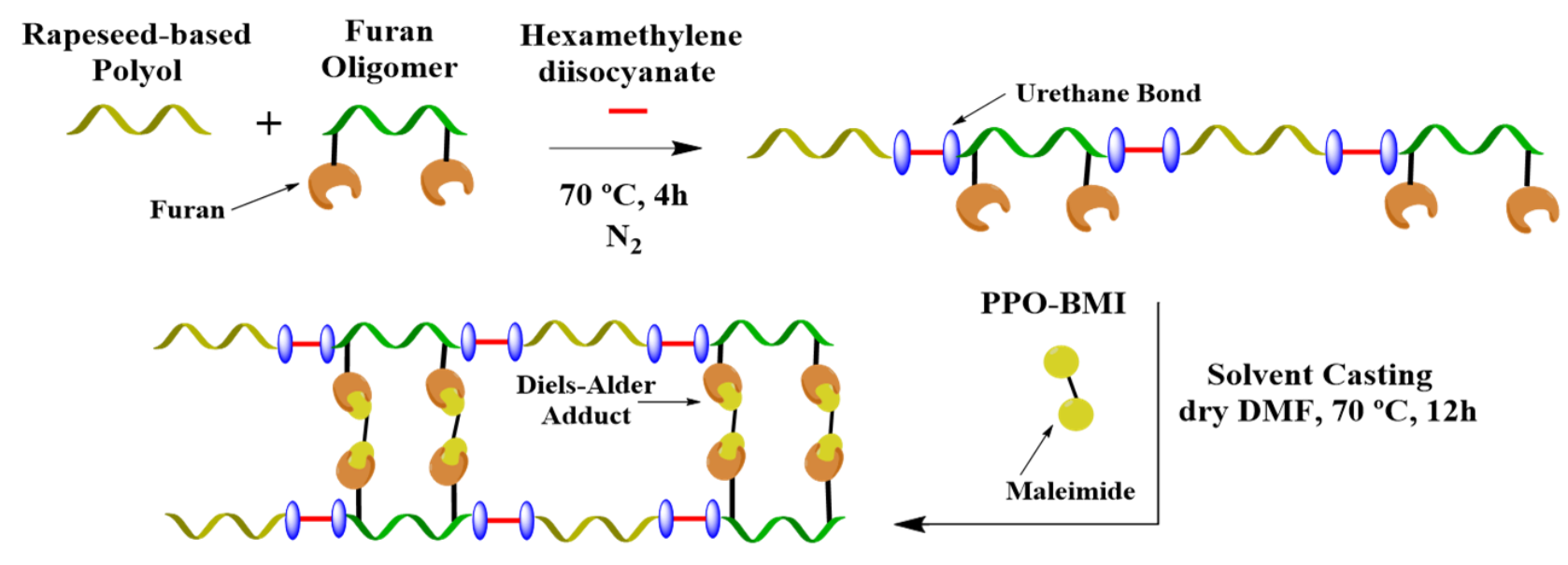

\section{Biobased Thermoreversible PU Network}

\section{Results and Discussion}

5 Analysis of the Synthesis of FO using Furan Oligomer

Scheme 1. Illustration of the general synthesis of biobased thermoreversible polyurethane-based systems

The acid moiety and alkene site of octadec-9-enoic acid (OA) were used as reaction sites to yield an oligomer with a diol structure containing pendent furan rings, as depicted in Scheme 2. OA was esterified using furan-2-ylmethanol (FM) at ambient temperature to yield furan-2-ylmethyl-oleate (FMO). The advantage of this type of esterification reaction (Steglich esterification) is that no energy source is required, minimizing the global energy requirement, in agreement with one of the main principles for a green chemistry. ${ }^{[28]}$ Nevertheless, this esterification reaction can also be accomplished using Candida Antarctic lipase B, an enzymatic catalyst, with greener conditions as explored by Sengupta et al. ${ }^{[29]}$. More recently, Muthusamy et al. used the same enzymatic catalyst to obtain furan based oligoesters. ${ }^{[30]}$ The use of enzymes as green catalysts for macromolecular synthesis has become prevalent in the recent years as highlighted by Kobayashi and coworkers. ${ }^{[31]}$ FTIR spectrum of FMO exhibits a predominant band at $1738 \mathrm{~cm}^{-1}$, confirming the presence of an ester carbonyl group and the furan heterocycle bands at 1503, 1375, 1347, 1228, $1080,920,885,739$ and $599 \mathrm{~cm}^{-1}$ (Figure 1). The appearance of the resonances of the methylene protons of the ester moiety at $5.1 \mathrm{ppm}$ and the furan ring protons at $6.36,6.39$ and $7.41 \mathrm{ppm}$ on the ${ }^{1} \mathrm{H}$ NMR spectrum of FMO confirms the expected structure (Figure 2). The technical grade oleic acid received contains small amounts of ethyl ester impurities as the saponification of the 
1 triglycerides takes place in ethanol. This is evidenced by the quartet signal associated the $\mathrm{CH}_{2}$ of 2 the ethyl ester at $4.21 \mathrm{ppm}$. The results of the analysis of ${ }^{13} \mathrm{C}$ NMR of FMO agreed with the 3 assigned structure as depicted in Figure S1 in the supplementary information (SI).

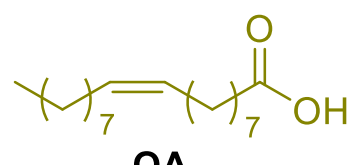

\section{OA}
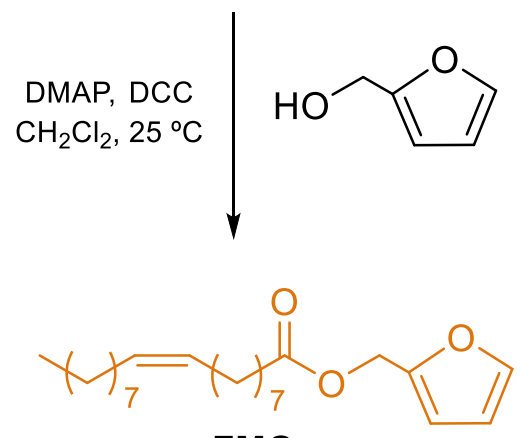

\section{FMO}
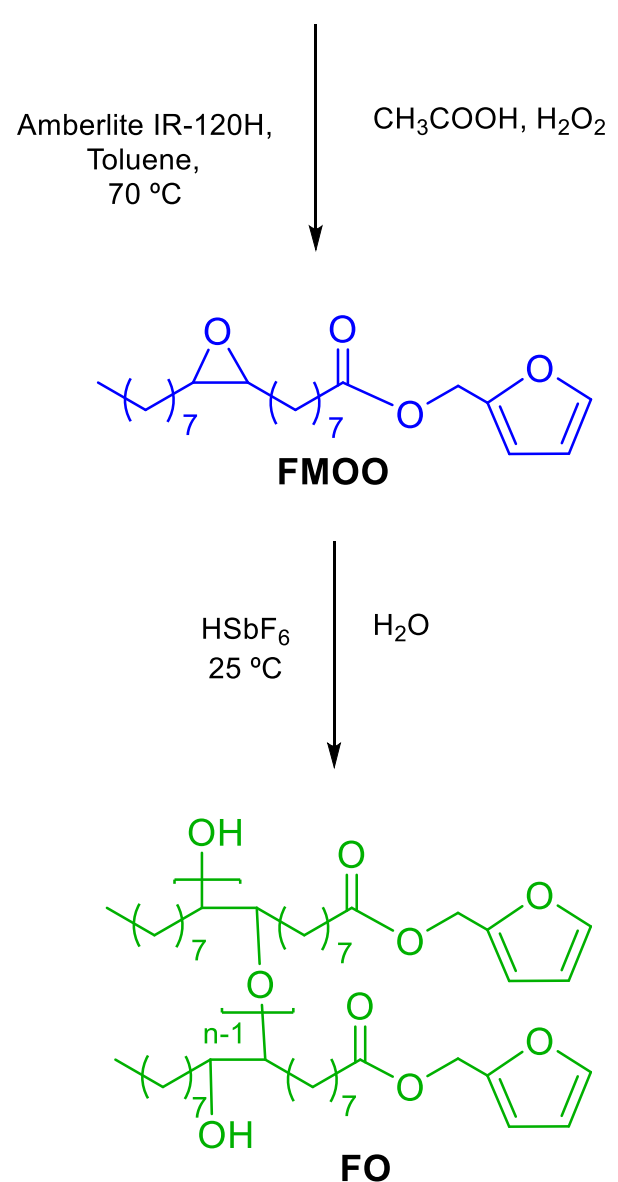




Figure 1. FTIR spectra of (a) OA (b) FMO (c) FMOO and (d) FO

4 Thereafter, FMO underwent an in situ epoxidation with the use of acetic acid, hydrogen peroxide $5 \quad\left(\mathrm{H}_{2} \mathrm{O}_{2}\right)$ and acid catalyst in toluene to yield furan-2-ylmethlyl 8-(3-octyloxiran-2-yl)octonoate 6 (FMOO). The acetic acid is converted to the oxidizing agent, peroxyacetic acid and is regenerated. 7 This type of epoxidation is nowadays routinely used on vegetable oils. ${ }^{\left[{ }^{32]}\right.}$ When compared to 8 conventional academic epoxidation based on meta-chloroperoxybenzoic acid (mCPBA) as an 9 oxidizing agent in solvent, ${ }^{[33]}$ in situ epoxidation uses milder oxidizing agents and globally adheres 10 better to green chemistry principles. The FTIR spectrum of FMOO (Figure 1c) shows the 11 disappearance of the double bonds at $3009 \mathrm{~cm}^{-1}$. By ${ }^{1} \mathrm{H}$ NMR analysis (Figure 2c) the structure is 12 confirmed by the disappearance of the vinyl and allyl protons at 5.35 and 1.99 ppm respectively, 13 and by the appearance of the epoxide and protons alpha to the epoxides at 2.90 and $1.45 \mathrm{ppm}$ 14 respectively. The results of the analysis of ${ }^{13} \mathrm{C}$ NMR of FMOO agreed with the assigned structure 15 as depicted in Figure S2 in SI. 
a)

a) $\underset{\mathrm{CHCl}_{3}}{\mathrm{OA}} \mathrm{b}$

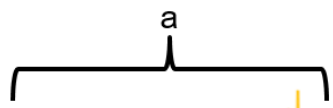

b)

$\downarrow^{\mathrm{CHCl}_{3}} \mathrm{a}^{7} \mathrm{a}$



c)

FMOO

d)

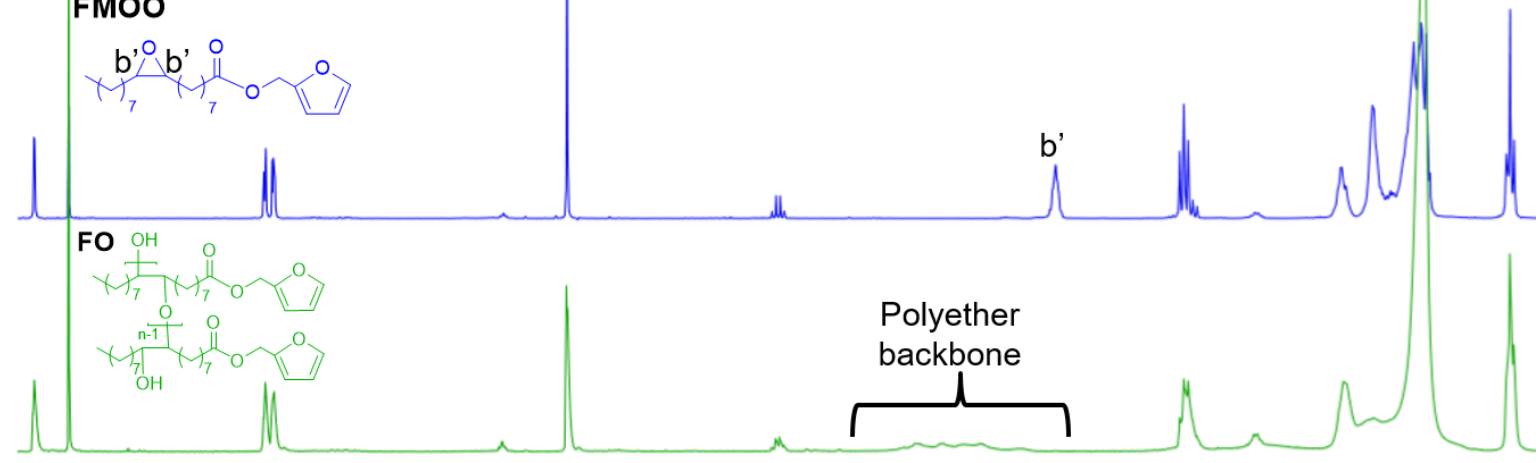

\section{$\begin{array}{lllllllllllll}7.0 & 6.5 & 6.0 & 5.5 & 5.0 & 4.5 & 4.0 & 3.5 & 3.0 & 2.5 & 2.0 & 1.5 & 1.0\end{array}$ Chemical Shift (ppm)}

Figure 2. ${ }^{1} \mathrm{H}$ NMR spectra (a) of OA (b) FMO (c) FMOO and (d) FO

An oligomer polyether diol was finally obtained by the acid-catalyzed ring-opening polymerization (ROP) of FMOO and denoted as Furan Oligomer (FO). This cationic polymerization was accomplished using fluoroantimonic acid, $\mathrm{HSbF}_{6}$, as it predominantly achieved oligoether species. ${ }^{[34]}$ It was observed that 1.5 w.t. $\%$ of initiator was required to achieve complete oligomerization. The reaction was performed in bulk and followed by ${ }^{1} \mathrm{H}$ NMR analysis. The FTIR spectrum (Figure 1d) exhibits the broad stretch of the hydroxyl groups at $3440 \mathrm{~cm}^{-1}$. The FO structure was further confirmed by ${ }^{1} \mathrm{H}$ NMR analysis (Figure $2 \mathrm{~d}$ ) by the disappearance of the epoxide protons and protons in alpha to the epoxides at 2.90 and $1.45 \mathrm{ppm}$, respectively, and the appearance of the formed polyether backbone between 3.00-3.60 ppm (for detailed integration see Figure S3). By ${ }^{13} \mathrm{C}$ NMR and ${ }^{13} \mathrm{C}$ NMR DEPT 135, as seen in Figure S4 and Figure S5 in the SI respectively, carbons associated to the polyether backbone corresponding to ether and carbon containing secondary hydroxyl groups clearly appear. Concurring with Lligadas et al., water was introduced in the oligomerization synthesis to suppress the occurrence of macrocyclization. This 
allowed for the nucleophilic attack of water to compete with intramolecular attacks, consequently favoring the proportion of linear species. Three different oligomers architectures were synthesized. As highlighted in Table 1, introducing higher water equivalents limits the oligomerization and yields overall higher hydroxyl values (HV) of the synthesized oligomers. The oligomer hydroxyl functionality was determined by using the $M_{n}$ and $H V$ and remains very close to two for all

6 oligomers synthesized. This was further confirmed by the MALDI-TOF MS analysis of Oligomer

7 Sample B as seen in Figure S6 and Figure S7 in SI, where the repeating units, $n$, varied from 2 to

8 9. The most intense peaks belonging to the series of oligomers with $n$ values of 3-5. The HV was

9 determined using ${ }^{31} \mathrm{P}-\mathrm{NMR}$ and quantification results can be found in Figure S8 and Table S2 in

10 SI. ${ }^{[35]}$ Quantitative ${ }^{1} \mathrm{H}$ NMR was used to determine the furan content (mmol furan/g) of FO and 11 quantification results are available in Figure S9 and Table S3 in SI. Oligomer B was then used for 12 the PU synthesis.

13

Table 1. Synthesis and properties of different FO obtained by cationic ROP of FMO

\begin{tabular}{|c|c|c|c|c|c|c|c|c|}
\hline $\begin{array}{l}\text { Oligomer } \\
\text { Sample }\end{array}$ & $\begin{array}{l}\text { Initiator } \\
\text { HSbF6 }_{6} \\
\text { (w.t. \%) }\end{array}$ & $\begin{array}{c}\mathrm{H}_{2} \mathrm{O} \\
(\mathrm{mol} \mathrm{\%})\end{array}$ & $\begin{array}{c}\text { Hydroxyl } \\
\text { Value by } \\
{ }^{31} \mathrm{P} \mathrm{NMR} \\
(\mathrm{mg} \\
\mathrm{KOH} / \mathrm{g})\end{array}$ & $\begin{array}{c}\text { Equivalent } \\
\text { Weight } \\
\text { (g/equiv) } \\
\text { [a] }\end{array}$ & $\begin{array}{c}\mathrm{Mn} \\
\text { (SEC; } \\
\mathrm{g} / \mathrm{mol})\end{array}$ & $\bigoplus^{[b]}$ & $\begin{array}{l}\text { Functionality } \\
\left(\mathrm{M}_{\mathrm{n}} / \mathrm{EW}\right)^{[\mathrm{c}]}\end{array}$ & $\begin{array}{c}\text { Furan } \\
\text { Content } \\
\text { by }{ }^{1} \mathrm{H} \\
\mathrm{NMR} \\
(\mathrm{mmol} / \mathrm{g})\end{array}$ \\
\hline A & 1.5 & 80 & 60 & 935 & 1179 & 1.75 & 1.90 & 1.89 \\
\hline B & 1.5 & 70 & 55 & 1020 & 1983 & 1.69 & 1.94 & 1.89 \\
\hline C & 1.5 & 60 & 49 & 1145 & 2222 & 1.94 & 1.94 & 1.74 \\
\hline
\end{tabular}

[a] Equivalent weight calculated from the hydroxyl value, EW. [b] Dispersity $=M_{w} / M_{n}$ [c] Obtained by the division of the experimental molar mass $\left(\mathrm{M}_{\mathrm{n}}\right)$ by the EW.

\section{Analysis of DA of FO and $\mathrm{N}$-Methylmaleimide}

FO was reacted with monofunctional $N$-methylmaleimide in DMSO at $65^{\circ} \mathrm{C}$, to study the DA adduct formation by ${ }^{1} \mathrm{H}$ NMR in absence of gelation. ${ }^{1} \mathrm{H}$ NMR attests the formation of the DA adduct (Figure 3a). Proton assignment was achieved using the ${ }^{1} \mathrm{H}$ NMR of initial compounds and comparison to the literature. ${ }^{[19 b, 36]}$ To quantify the conversion, proton signals, $f_{1}$ and $f_{4}$ (in the furan) and $m_{2}$ (in the maleimide) and $f_{1}{ }^{\prime}, f_{4}$ and $m_{2}$ (in the adduct) were used as they are free from overlap with other signals (Figure 3a). The conversion was calculated in accordance with Equation 1 for proton set $f_{1}$ and $f_{1}$ as follows; where $I_{n} t_{f 1}$ and $I n t_{f 1}$, represent the integral values of their respective protons: 


$$
X(\%)=\frac{\operatorname{Int} f_{f 1^{\prime}}}{\operatorname{Int}_{f 1}+\operatorname{Int}_{f 1^{\prime}}} * 100
$$

2 Similar results could be obtained with proton sets $\mathrm{f}_{4}, \mathrm{f}_{4}$ and $\mathrm{m}_{2}, \mathrm{~m}_{2}^{\prime}$. The evolution of the conversion 3 with respect to time at $65{ }^{\circ} \mathrm{C}$ is depicted on Figure $3 \mathrm{~b}$. An equilibrium conversion of $65 \%$ was 4 attained after 121 hours of reaction time, as similarly reported in literature. ${ }^{[37]}$ Furthermore, proton 5 signals, $f_{1}{ }^{\prime}$ and $m_{2}$, were used to quantify the evolution of two diastereomers of the DA adduct 6 (endo and exo) with respect to time (Figure $3 \mathrm{~b}$ ), as the chemical shift differs slightly for each 7 diastereomer. The endo adduct which is kinetically favored, ${ }^{[36]}$ is first formed at $62 \%$. As the 8 reaction time progresses, the thermodynamically stable exo diastereomer becomes the 9 predominant entity ( 91 w.t. \%) after 121 hours of reaction time. 
a)
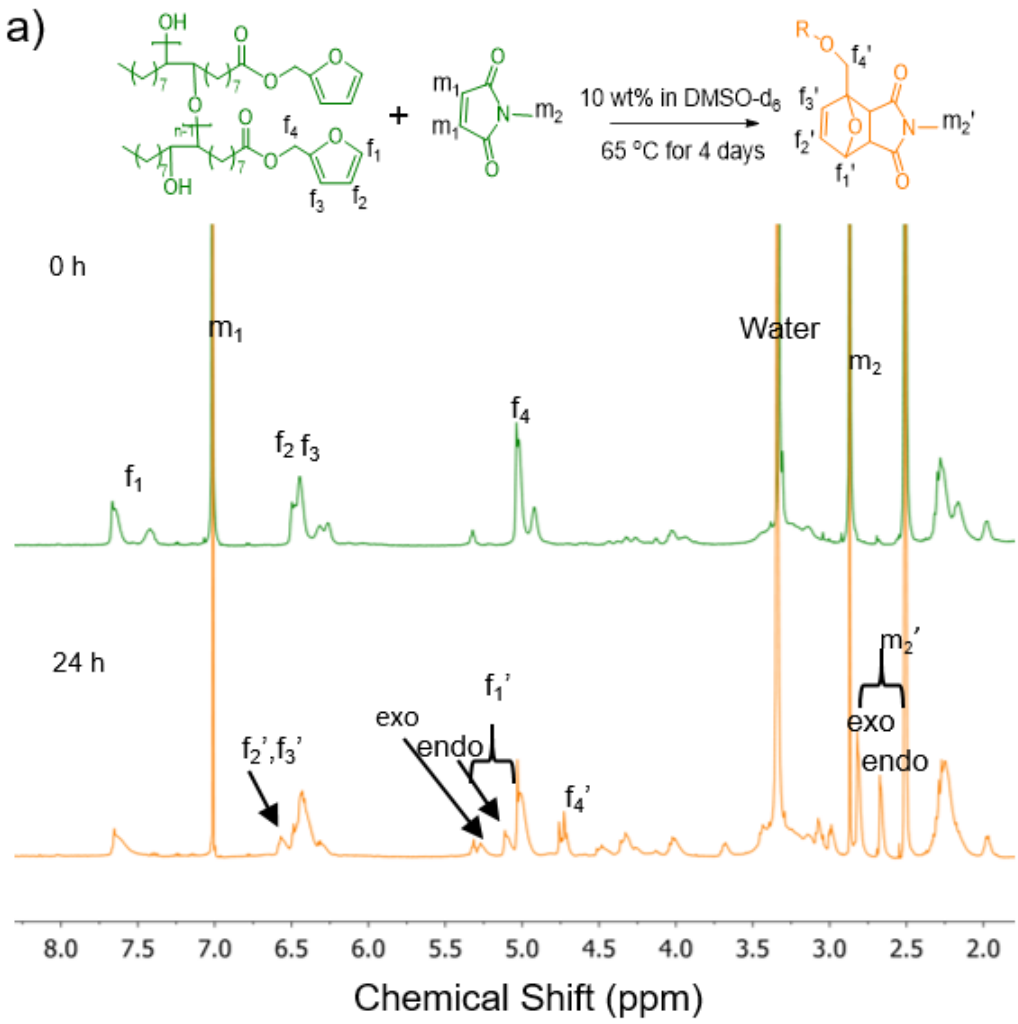

b)



2 Figure 3. (a) ${ }^{1} \mathrm{H}$ NMR spectra of mixture of $\mathrm{FO}$ and $\mathrm{N}$-methylmaleimide after 0 and $24 \mathrm{~h}$, (b) conversion 3 and percentage of endo structure with respect to time at $65^{\circ} \mathrm{C}$. 


\section{Analysis of DA and r-DA Reactions between FO and a Bismaleimide}

To test and simulate the formation of DA adducts between PU chains, the FO was reacted with PPO BMI. DSC was used to monitor the formation of the DA adducts and the r-DA reaction. A stoichiometric mixture of FO and PPO BMI was heated from -30 to $175 \stackrel{\circ}{\circ}$. As controls, FO and PPO BMI were separately investigated under the same conditions. As seen in the thermograms reported in Figure 4a, no thermodynamic phenomena take place for each separate entity. However, in the thermogram of the mixture (orange), an exothermic peak begins to appear between 50 to $60^{\circ} \mathrm{C}$, indicating the DA reaction. Two endothermic peaks, corresponding to the $\mathrm{r}$ DA, follow the exothermic peak. The first one, between 90-120 ${ }^{\circ} \mathrm{C}$, corresponds to the r-DA of the endo diastereomer, while the second one refers to the r-DA of the exo diastereomer, between $120-150^{\circ} \mathrm{C} .^{[36]}$

The thermoreversibility of the network formed between the FO and the BMI was further qualitatively studied by dissolving the mixture in DMSO and exposing it to different heating cycles. As depicted in Figure $4 \mathrm{~b}$-i, the mixture is first completely soluble in DMSO. Once exposed to 60 ${ }^{\circ} \mathrm{C}$ for 24 hours, a gel is formed by cross-linkage (Figure $\left.4 b-i i\right)$. The mixture was then exposed to $120^{\circ} \mathrm{C}$ for $1 \mathrm{~h}$, causing the disassembly of the network due to the r-DA reaction (Figure $4 b$-iii). When repeating the heating cycle, the same phenomenon took place (Figure $4 \mathrm{~b}$-iv). To further evidence the DA reaction, the mixture was studied prior and after gel formation by FTIR. Before crosslinking, the FTIR spectrum of the mixture contains signals of free furan (739 and $1503 \mathrm{~cm}^{-1}$ ) and maleimide rings (695 and $826 \mathrm{~cm}^{-1}$ ) (Figure 4c). After gel formation, the FTIR spectrum exposes a complete disappearance of the respective free furan and maleimide ring signals. To quantitatively study the DA reaction and r-DA between FO and BMI, the rheological behavior of gel formation between the two entities was evaluated by a dynamic experiment. As seen in Figure $\mathrm{S} 10$, the gelation reaction was analyzed by a time sweep test at $60{ }^{\circ} \mathrm{C}$ at $1 \%$ strain and $1 \mathrm{~Hz}$, while recording the variation of the two dynamic moduli. Gelation occurs when the moduli cross over at 1740 s (29 mins, (G' G" $650 \mathrm{~Pa}$ ). Thereafter, heating steps were imposed to evaluate the thermoreversibility of the gel, $60^{\circ} \mathrm{C}$ for the DA and $120{ }^{\circ} \mathrm{C}$ fore r-DA. During the r-DA heating steps, the gel would disassemble and the two moduli shoot back to zero. The gel was reassembled two more times, each time leading to quicker gelation times. This thus proves the thermoreversibility of the crosslinking points of the PU materials made using these two building blocks. 
a)
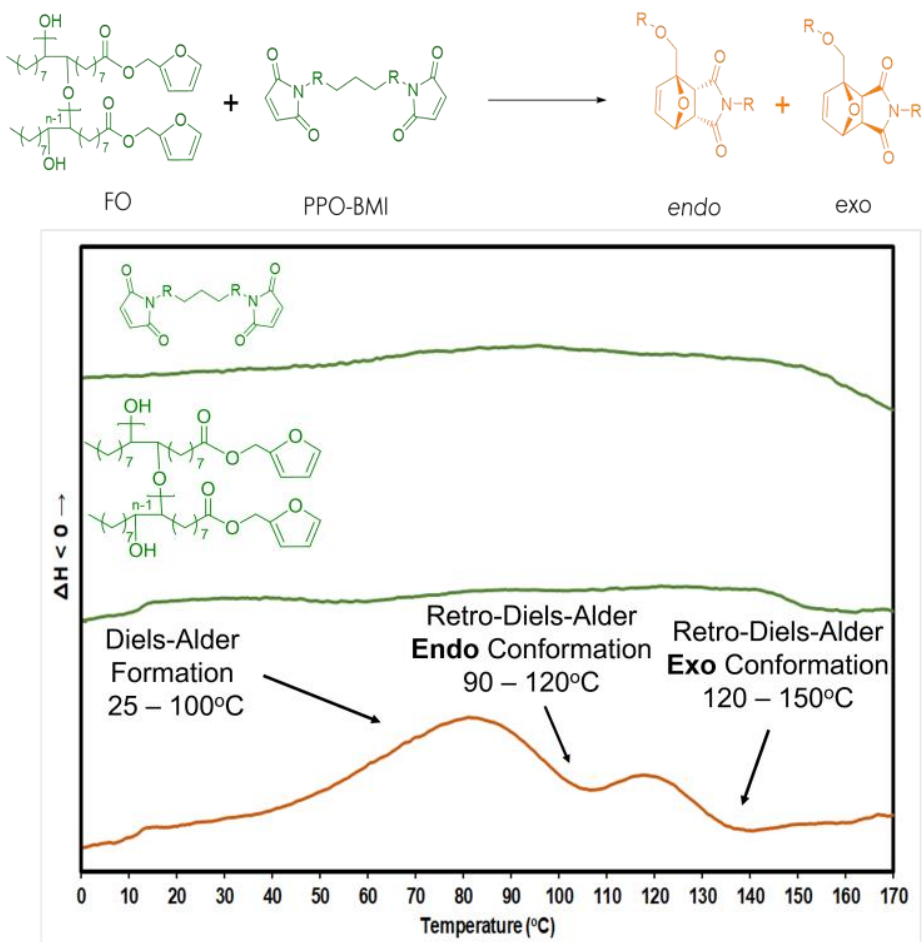

b)


iv)




c)

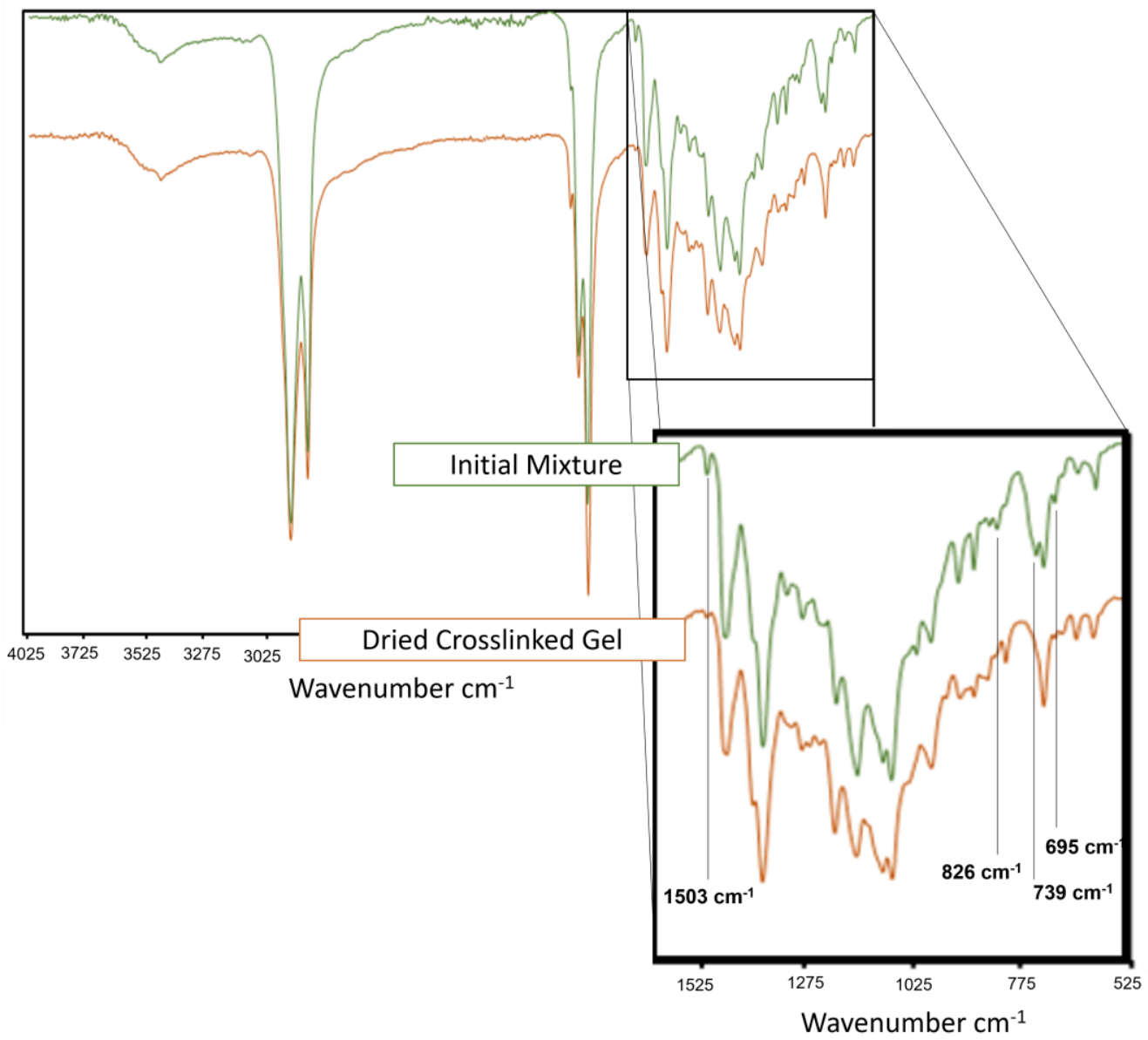

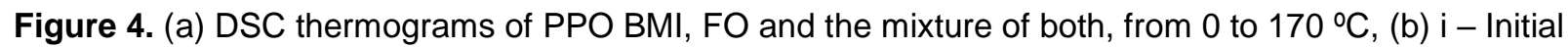
mixture of $\mathrm{FO}$ and PPO BMI, ii - mixture after $24 \mathrm{~h}$ at $60^{\circ} \mathrm{C}$, iii - mixture after additional $1 \mathrm{~h}$ at $120{ }^{\circ} \mathrm{C}$, iv mixture after additional $24 \mathrm{~h}$ at $60^{\circ} \mathrm{C}$, (c) FTIR spectra of initial mixture (green) and final dried crosslinked gel (orange).

\section{Analysis of the Synthesis of Biobased Crosslinked PU containing FO and BMI}

The synthesis of crosslinked biobased PUs containing thermoreversible DA adducts was obtained by using FO and PPO BMI. Scheme 1 illustrates the route for the preparation of the control (linear PUs - reaction 1) systems and crosslinked PUs (reactions 1 and 2). Different types of PUs were prepared by varying the proportion of FO in a PU system by the polyaddition between the biobased polyester polyol (chemical structure found in Figure 5) and hexamethylene di-isocyanate (HDI). The FO content in the PU systems was varied from 0 to $30 \%$ of the total hydroxyl moles required to synthesize PUs with a final $\mathrm{NCO}: \mathrm{OH}$ ratio of 1.05. PUs were obtained without HS (segments synthesized with short diols and di-isocyanates) to study the effect of the FO on a model, a simple system. The nomenclature of all PU systems synthesized is summarized in Table 2 . The different control PU systems, with varying amounts of FO content were denoted as PU-FO-0, PU-FO-10, 
1 PU-FO-20, and PU-FO-30. Thermoreversible crosslinked PU systems were obtained by dissolving 2 the corresponding linear PU in dry DMF, adding the required amount of PPO BMI and letting the 3 solution stir overnight at $70{ }^{\circ} \mathrm{C}$, to allow the DA reaction to take place. These solutions then 4 underwent solvent casting in a PTFE square mold for $48 \mathrm{~h}$ at $70 \stackrel{\circ}{\circ}$ followed by $24 \mathrm{~h}$ under vacuum 5 at $70 \stackrel{\circ}{\circ}$ to yield a crosslinked PU. Crosslinked PUs containing the required PPO BMI mass to 6 yield a 1:1 furan to maleimide ratio were denoted as PU-FO-10XL, PU-FO-20XL and PU-FO7 30XL. Two additional crosslinked PUs were synthesized using the linear PU-FO-20 but with 1: 0.7 8 and 1: 0.5 furan and maleimide ratios and denoted as PU-FO-20XL-0.7BMI and PU-FO-20XL$9 \quad 0.5 \mathrm{BMI}$, respectively.

10



Figure 5. Chemical structure of the biobased polyester polyol supplied by the provider. Polyol based on dimeric fatty acids from rapeseed oil. 
Table 2. Linear PU (control) and crosslinked systems: nomenclature and corresponding formulations.

\begin{tabular}{ccccc}
$\begin{array}{c}\text { PU System } \\
\text { Nomenclature }\end{array}$ & $\begin{array}{c}\text { Type of } \\
\text { System }\end{array}$ & $\begin{array}{c}\text { Furan } \\
\text { Oligomer (FO) } \\
\text { Content [a] } \\
(\%)\end{array}$ & $\begin{array}{c}\text { Rapeseed } \\
\text { Polyol Content } \\
{[\mathrm{a}]} \\
(\%)\end{array}$ & $\begin{array}{c}\text { PPO BMI } \\
\text { Equivalents }{ }^{[b]}\end{array}$ \\
\hline PU-FO-0 & Linear & 0 & 100 & 0 \\
PU-FO-10 & Linear & 10 & 90 & 0 \\
PU-FO-10XL & Crosslink & 10 & 90 & 1 \\
PU-FO-20 & Linear & 20 & 80 & 0 \\
PU-FO-20XL & Crosslink & 20 & 80 & 1 \\
PU-FO-20- & Crosslink & 20 & 80 & 0.7 \\
0.7BMI & & 20 & 80 & 0.5 \\
PU-FO-20- & Crosslink & 30 & 70 & 0 \\
0.5BMI & Linear & 30 & 70 & 1 \\
PU-FO-30 & Crosslink & &
\end{tabular}

2 All PU systems post curing (linear and crosslinked) were insoluble in conventional solvents $3 \quad\left(\mathrm{CHCl}_{3}, \mathrm{DMSO}, \mathrm{THF}, \mathrm{DMF}\right)$ and thus were examined by FTIR. It has been shown that symmetrical 4 di-isocyanates such as HDI increase the crystallinity and hard segment packing of polyurethanes 5 which may account for the lack of solubility that occurs in the presented networks. ${ }^{[38]} \mathrm{A}$ comparison 6 of the FTIR spectra of FO, biobased polyester rapeseed polyol, PU-FO-30, PU-FO-30-XL and 7 PPO BMI is displayed in Figure 6. In Figure 6c of the FTIR spectrum PU-FO-30, the disappearance 8 the hydroxyl stretches (approximately at $3440 \mathrm{~cm}^{-1}$ ) associated to the hydroxyls of FO and 9 rapeseed polyol is observed. Consequently, the appearance of vibrations at 3380 and $1550 \mathrm{~cm}^{-1}$ 10 corresponding to $-\mathrm{N}-\mathrm{H}$ stretching and bending respectively of urethane group, whereas the ester 11 urethane stretch present itself at a shouldering located at $1700 \mathrm{~cm}^{-1}$. The FTIR spectrum of PU12 FO-30XL (Figure 6d) displays a similar spectrum than that of PU-FO-30. However, the addition of 13 PPO BMI to yield a crosslinked system results in the appearance of the carbonyls of the 14 maleimides at $1705 \mathrm{~cm}^{-1}$. Moreover, as the PU-FO-30XL is crosslinked via DA reaction, the 
disappearance of furan heterocycle and $\mathrm{C}-\mathrm{H}$ bending of maleimide ring $\left(826\right.$ and $\left.692 \mathrm{~cm}^{-1}\right)$ is observed.

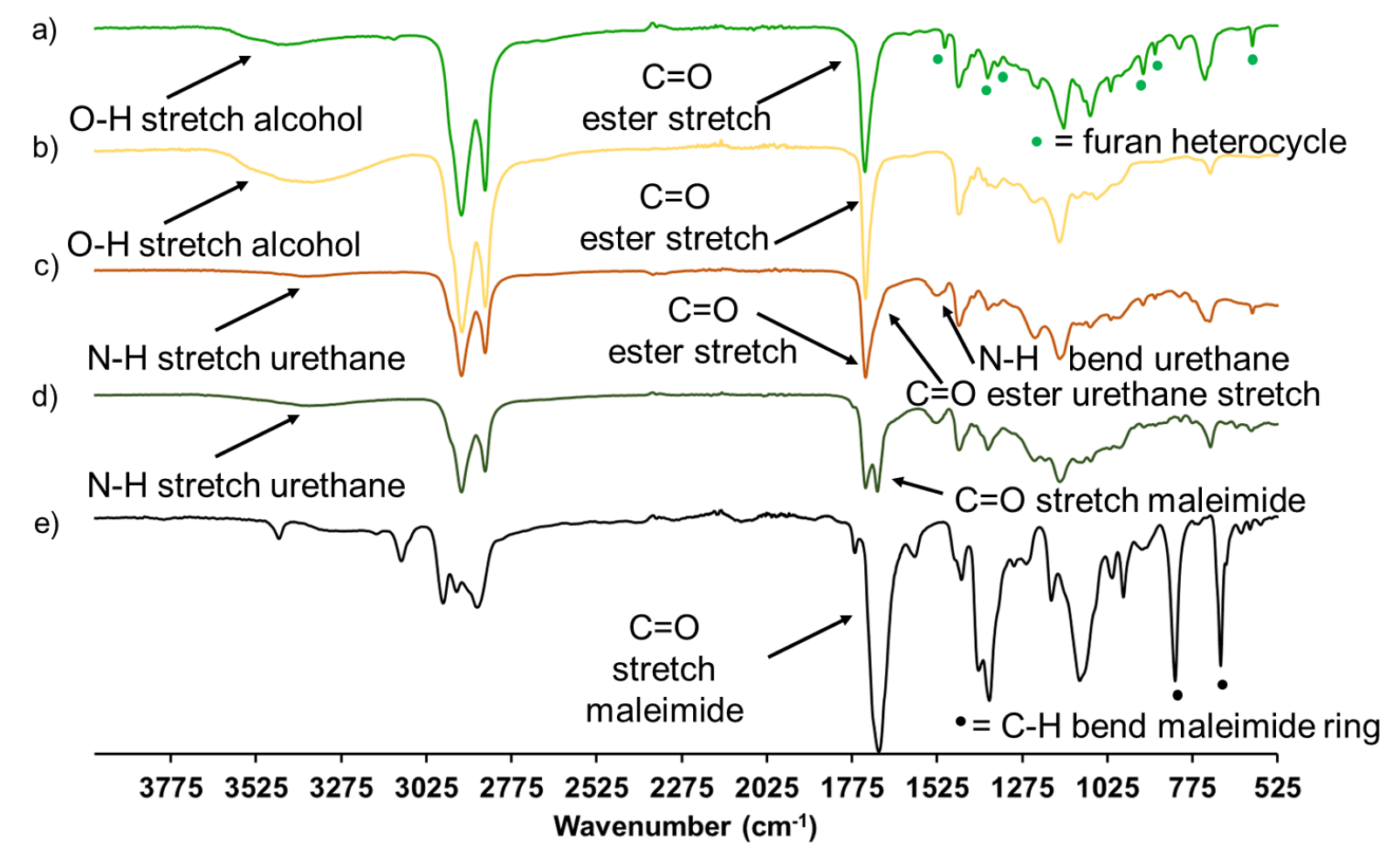

Figure 6. FTIR spectra of (a) FO (b) Rapeseed Polyol (c) PU-FO-30 (d) PU-FO-30XL (e) PPO BMI

4 Characterization of Biobased Crosslinked PUs

5 The thermal stability of all PU materials was evaluated by TGA. Detailed TGA results are found in

6 Figure $\mathrm{S} 11$ in $\mathrm{SI}$. As exhibited in Table 3, the initial thermal degradation $\left(\mathrm{T}_{5 \%}\right)$ for all materials 7 begins at temperatures above that of the r-DA reaction. This is indicative that reprocessing and 8 disassembly of crosslinked points is thus possible without thermal degradation, although the 9 introduction of the FO seems to decrease the $\mathrm{T}_{5 \%}$ (from 337 to $230^{\circ} \mathrm{C}$ for PU-FO-0 to PU-FO-30).

10 Furthermore, the respective crosslinked material have lower $T_{5 \%}$, with except of PU-FO-10XL. The 11 glass transition temperatures $\left(\mathrm{T}_{\mathrm{g}}\right)$ were measured by DSC and results are summarized in Table 123 . The $\mathrm{T}_{\mathrm{g}}$ of crosslinked materials were recorded using a single heating ramp, from $-80{ }^{\circ} \mathrm{C}$ to $175^{\circ} \mathrm{C}$ in order to avoid any significant degradation as indicated by TGA results. When comparing a control PU-FO-30 with its respective crosslinked PU counterpart (PU-FO-30XL), the $\mathrm{T}_{g}$ increases due to a high level of crosslinking. Furthermore, as seen in Figure 7, the thermograms of crosslinked PUs exhibit the presence of an endothermic peak between 90 and $150{ }^{\circ} \mathrm{C}$ corresponding to the r-DA reaction, whereas, their control PU counterparts are flat-lined as no BMI is present. Materials containing increased amounts of FO, (and consequently increased 
1 crosslinking density) logically exhibit a more prominent endothermic r-DA peak between 90 and $2150 \stackrel{\circ}{\circ}$. A slight endothermic peak seems to appear in all crosslinked materials of Figure 7 3 between 30 to $60 \stackrel{\circ}{\circ}$. As previously mentioned, crosslinked materials are evaluated by a single 4 heating ramp form -80 to $175^{\circ} \mathrm{C}$. These endothermic peaks were present as well in linear material 5 upon first heating but disappeared upon the second heating when as the thermal history of the 6 material has been erased. Thus, these slight endothermic peaks appear to be associated the 7 thermal history of the material. Detailed DSC results are found in Figure S12.

Table 3. Characterizations of synthesized biobased polyurethanes.

\begin{tabular}{|c|c|c|c|c|c|c|c|}
\hline PU System & $\begin{array}{l}\text { TGA } \\
\mathrm{T}_{5 \%} \\
\left({ }^{\circ} \mathrm{C}\right)\end{array}$ & $\begin{array}{c}\text { DSC } \\
\mathrm{T}_{g} \\
\left({ }^{\circ} \mathrm{C}\right)\end{array}$ & $\begin{array}{c}\text { Young's } \\
\text { Modulus } \\
\text { E } \\
(\mathrm{MPa}) \\
\end{array}$ & $\begin{array}{c}\text { Tensile } \\
\text { Strength } \\
\sigma \\
(\mathrm{Mpa}) \\
\end{array}$ & $\begin{array}{c}\text { Elongation } \\
\varepsilon \\
(\%)\end{array}$ & $\begin{array}{c}\text { Swelling Ratio } \\
\text { in DMF } \\
(\%)\end{array}$ & $\begin{array}{c}\text { Insoluble } \\
\text { Fraction } \\
(\%)\end{array}$ \\
\hline PU-FO-0 & 337 & -50 & $\begin{array}{c}0.39 \\
\pm 0.03\end{array}$ & $\begin{array}{c}0.58 \\
\pm 0.02\end{array}$ & $\begin{array}{r}563 \\
\pm 36\end{array}$ & $\begin{array}{r}36.9 \\
\pm 1.8\end{array}$ & $\begin{array}{r}96.4 \\
\pm 0.3\end{array}$ \\
\hline PU-FO-10 & 327 & -51 & $\begin{array}{c}0.14 \\
\pm 0.01\end{array}$ & $\begin{array}{c}0.36 \\
\pm 0.02\end{array}$ & $\begin{array}{l}368 \\
\pm 27\end{array}$ & $\begin{array}{r}51.6 \\
\pm 2.3\end{array}$ & $\begin{array}{r}94.4 \\
\pm 0.6\end{array}$ \\
\hline PU-FO-10XL & 333 & -51 & $\begin{array}{c}0.32 \\
\pm 0.01\end{array}$ & $\begin{array}{c}0.51 \\
\pm 0.03\end{array}$ & $\begin{array}{r}409 \\
\pm 54\end{array}$ & $\begin{array}{r}44.3 \\
\pm 0.6\end{array}$ & $\begin{array}{l}95.0 \\
\pm 0.9\end{array}$ \\
\hline PU-FO-20 & 298 & -51 & $\begin{array}{c}0.11 \\
\pm 0.01\end{array}$ & $\begin{array}{c}0.38 \\
\pm 0.03\end{array}$ & $\begin{array}{l}288 \\
\pm 4\end{array}$ & $\begin{array}{r}58.5 \\
\pm 3.4\end{array}$ & $\begin{array}{r}92.9 \\
\pm 0.6\end{array}$ \\
\hline PU-FO-20XL & 267 & -50 & $\begin{array}{c}0.32 \\
\pm 0.01\end{array}$ & $\begin{array}{c}0.50 \\
\pm 0.01\end{array}$ & $\begin{array}{l}232 \\
\pm 2\end{array}$ & $\begin{array}{r}46.9 \\
\pm 0.1\end{array}$ & $\begin{array}{r}95.2 \\
\pm 2.9\end{array}$ \\
\hline $\begin{array}{c}\text { PU-FO-20- } \\
0.7 \mathrm{BMI}\end{array}$ & 287 & -51 & $\begin{array}{c}0.30 \\
\pm 0.01\end{array}$ & $\begin{array}{c}0.40 \\
\pm 0.02\end{array}$ & $\begin{array}{l}208 \\
\pm 2\end{array}$ & $\begin{array}{r}48.2 \\
\pm 6.3\end{array}$ & $\begin{array}{r}92.0 \\
\pm 2.9\end{array}$ \\
\hline $\begin{array}{c}\text { PU-FO-20- } \\
0.5 \mathrm{BMI}\end{array}$ & 293 & -50 & $\begin{array}{c}0.26 \\
\pm 0.01\end{array}$ & $\begin{array}{c}0.32 \\
\pm 0.01\end{array}$ & $\begin{array}{l}232 \\
\pm 11\end{array}$ & $\begin{array}{r}55.7 \\
\pm 3.0\end{array}$ & $\begin{array}{r}90.6 \\
\pm 1.2\end{array}$ \\
\hline PU-FO-30 & 250 & -55 & NA & NA & NA & $\begin{array}{l}146.1 \\
\pm 7.4\end{array}$ & $\begin{array}{r}77.5 \\
\pm 0.8\end{array}$ \\
\hline PU-FO-30XL & 234 & -51 & $\begin{array}{c}0.57 \\
\pm 0.09 \\
\end{array}$ & $\begin{array}{r}0.49 \\
\pm 0.04 \\
\end{array}$ & $\begin{array}{l}107 \\
\pm 9 \\
\end{array}$ & $\begin{array}{l}70.4 \\
\pm 2.7 \\
\end{array}$ & $\begin{array}{r}92.5 \\
\pm 0.6\end{array}$ \\
\hline
\end{tabular}




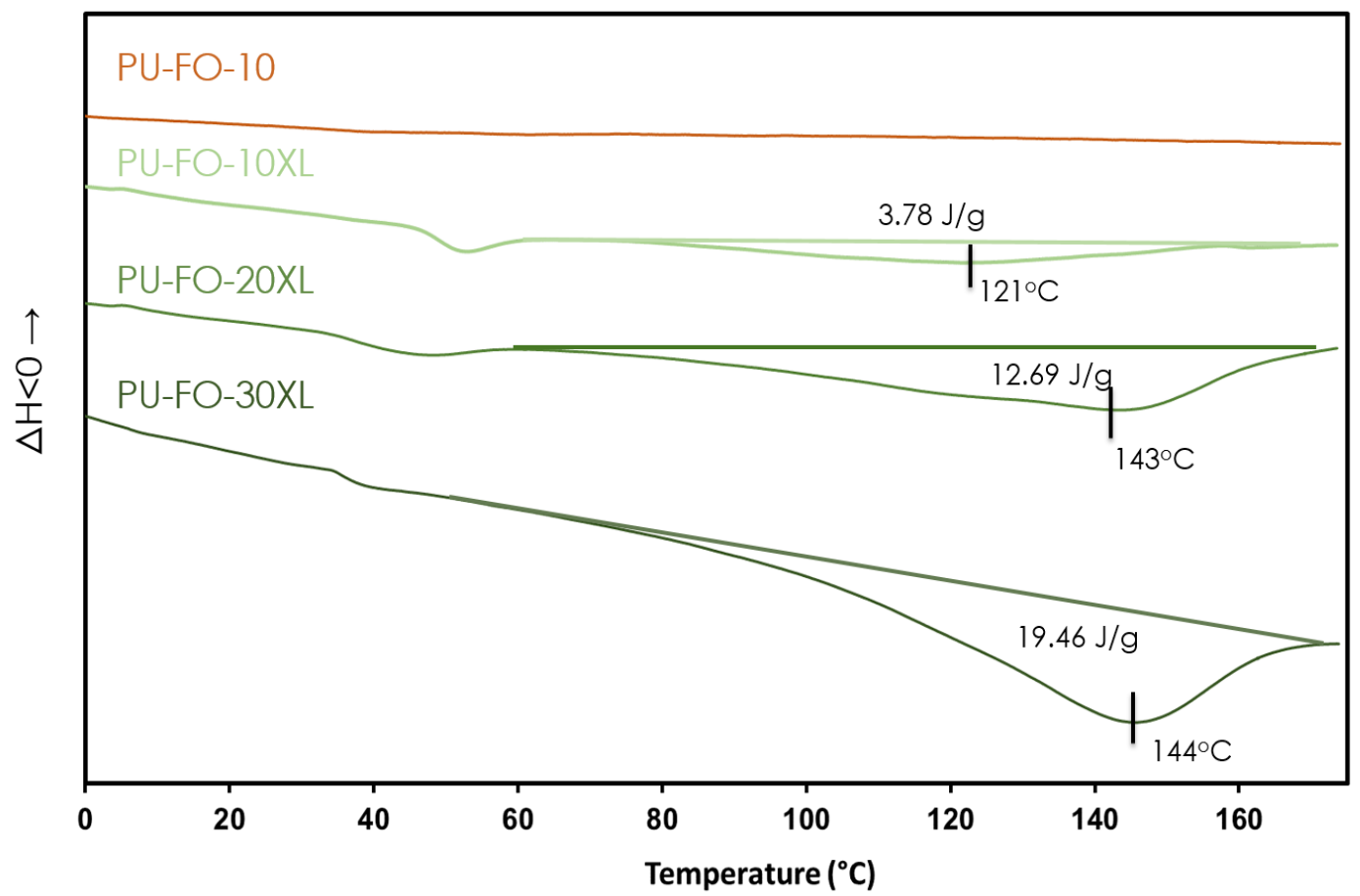

Figure 7. Thermograms of four PUs: PU-FO-10, PU-FO-10XL, PU-FO-20XL and PU-FO-30XL from 0 to $175^{\circ} \mathrm{C}$.

The mechanical properties of the PUs were evaluated by uniaxial tensile tests at room temperature. The sticky-like and weak behavior of control PU, PU-FO-30, rendered the material non-testable because it was non-processable for dumbbell shaping, as molding these samples was impossible. When examining Table 3 and more specifically control PUs results, the incorporation of $\mathbf{F O}$ into the PU structure weakens the material as there is an apparent decrease in tensile strength and Young's modulus of PU-FO10, PU-FO-20 in comparison to PU-FO-0. Furthermore, the addition of $\mathrm{FO}$ also reduces the elasticity of the material as the elongation of PUFO-10, PU-FO-20 is decreased with respect to PU-FO-0. Nevertheless, when examining the mechanical properties of crosslinked PUs: PU-FO-10XL, PU-FO-20XL and PU-FO-30XL, the crosslinking by DA improves the tensile strength of the materials, but most notably the Young's modulus.

From Figure 8, which exhibits the stress-strain curves of PU-FO-0, PU-FO-10XL, PU-FO-20XL and PU-FO-30XL, it can be deduced that by increasing the portion of $F O$ in the PU structure and crosslinking by PPO BMI, the material properties vary from a thermoplastic elastomer (PU-FO-0) to a thermoset material (PU-FO-30XL). Furthermore, it was evidenced that mechanical properties 
can be further tuned by varying the equivalents of PPO BMI introduced into the material. This is evidenced by the mechanical properties of PU-FO-20XL-0.7BMI and PU-FO-20XL-0.5BMI, whereby varying the equivalents of PPO BMI between 0.7 and 0.5 to furan equivalents resulted in tensile strengths and Young's modulus in an intermediate range between PU-FO-20 and PU-FO20XL (Table 3).

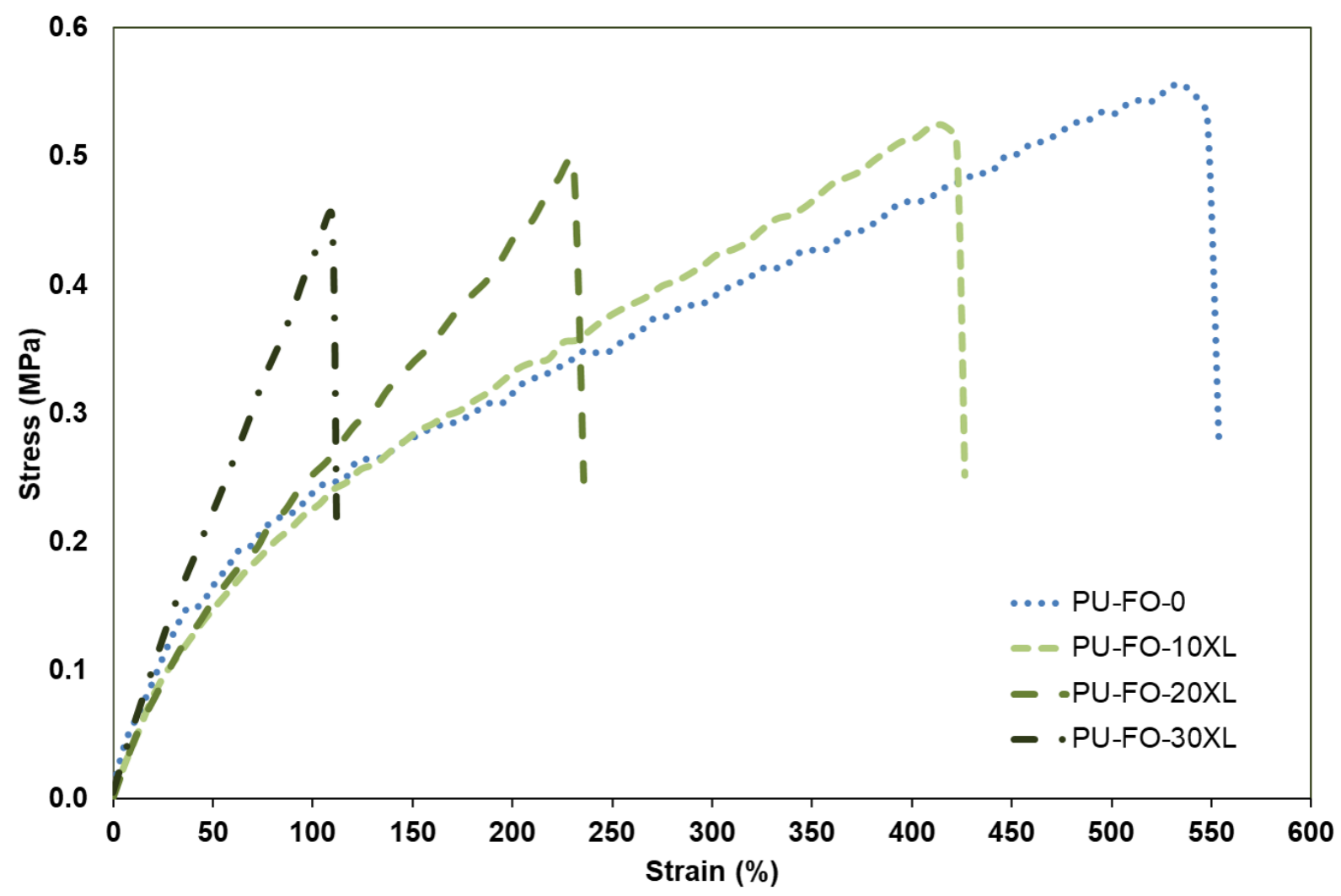

Figure 8. Stress-strain curves of PU-FO-0, PU-FO-10XL, PU-FO-20XL and PU-FO-30XL.

All PU materials were lastly characterized by swelling test in DMF. As seen in Table 3, when first examining linear materials PU-FO-0, PU-FO10, PU-FO-20, and PU-FO-30, it can be observed that the polymer networks experience higher swelling when increasing the amount of FO in the polymer architecture. Contrastingly, due the crosslinking by DA reaction, the results of crosslinked PUs yield considerably lower swelling ratios in comparison to their respective control PU. The most considerable effect of DA crosslinking is seen for the highest crosslinked content, between PU-FO-30 to PU-FO-30XL, where the swelling ratio decreased from 146 to $70 \%$, respectively, and the insoluble fraction increases from 78 to 93\%, respectively. Except PU-FO-30, all PU material were relatively insoluble. Furthermore, the swelling ratio of PU material PU-FO-20XL-0.7BMI and 
PU-FO-20XL-0.5BMI yields intermediate results between the crosslinked material, PU-FO-20XL and the linear control PU, PU-FO-20. This is a testament of tunable properties when varying not only the FO content but as well the PPO BMI concentration.

\section{Thermoreversibility of Biobased Crosslinked PU leading to Remendable and Self-healing Behaviors}

Preamble studies conducted to prove the thermoreversible between $\mathbf{F O}$ and the monofunctional $\mathrm{N}$-methylmaleimide or PPO BMI permitted to test and simulate the thermoreversibility of crosslinked PU by the DA and r-DA reaction. To first evaluate the thermoreversibility of crosslinked marterials, PU-FO-20XL was examined by FTIR after exposing the material to different heating cycles. As depicted in Figure 9, when heating the material for $2 \mathrm{~h}$ at $120{ }^{\circ} \mathrm{C}$, free maleimide ring peaks appear prevalent at 692 and $825 \mathrm{~cm}^{-1}$ due the occurrence the r-DA reaction. These free maleimide ring peaks disappear once the DA reaction takes place, when the material is reexposed to $70 \stackrel{\circ}{\circ}$ for $20 \mathrm{~h}$. This heating cycle was repeated and yields the same result, as seen in Figure 9. This indicates that the materials crosslinked by DA have the potential of being reprocessable and could be self-healing.

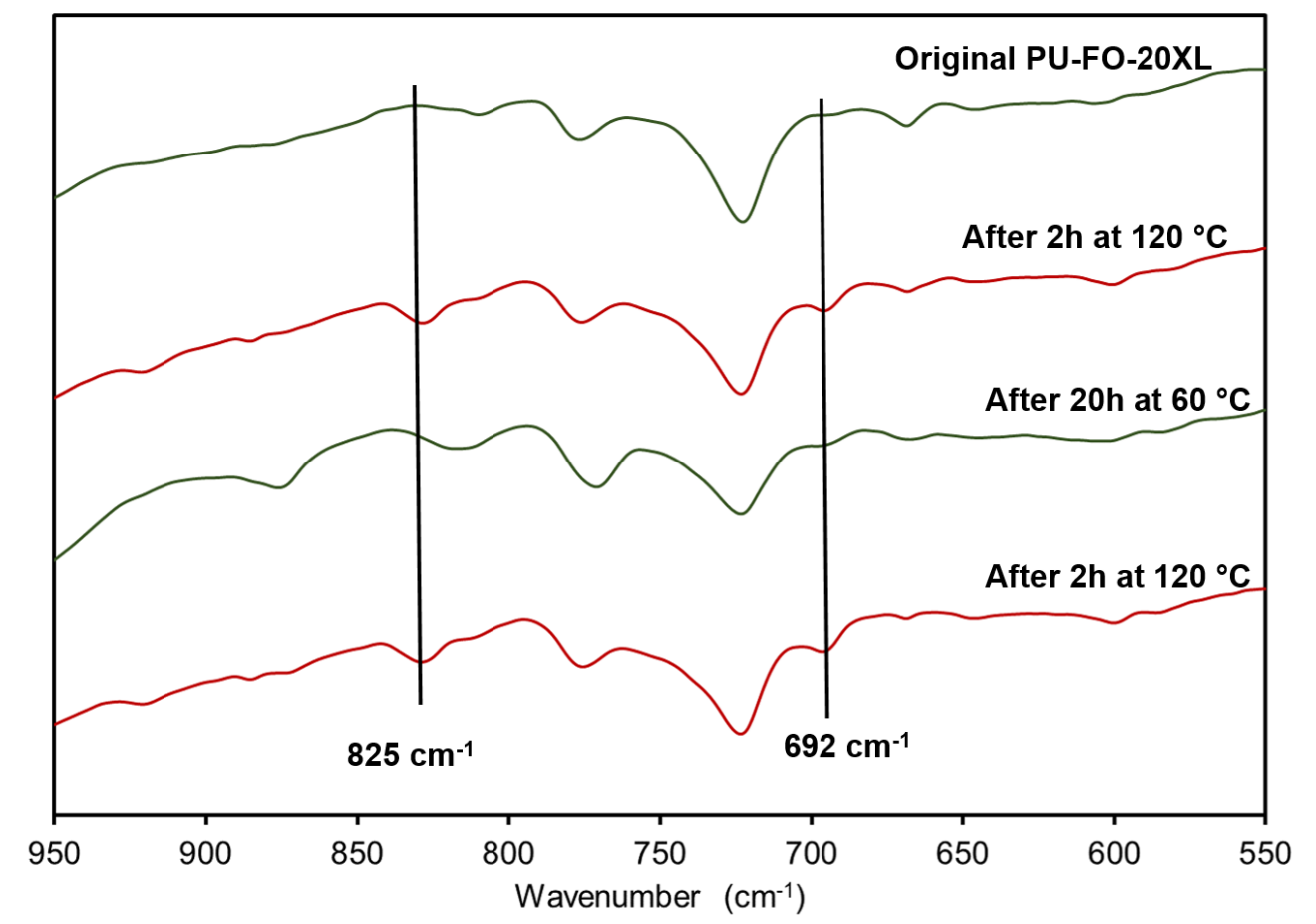

Figure 9. FTIR spectra of original PU-FO-20XL followed by: PU-FO-20XL heated for $2 \mathrm{~h}$ at $120^{\circ} \mathrm{C}$, PUFO-20XL heated for $20 \mathrm{~h}$ at $60^{\circ} \mathrm{C}$ and PU-FO-20XL heated for $2 \mathrm{~h}$ at $120^{\circ} \mathrm{C}$. 
Reprocessability was also studied on PU-FO-30XL. It was first processed by solvent casting and then characterized (Table 4). This material was then reprocessed by compression molding at $150{ }^{\circ} \mathrm{C}$ for 25 minutes. The material was cured at $60^{\circ} \mathrm{C}$ in the oven for 48 hours and post cured for 24 hours at room temperature. The uniaxial tensile test and $T_{g}$ were studied for this material labeled PU-FO-30XL-RP1. The material was then reprocessed, re-evaluated, and labeled PU-FO30XL-RP2. The results are summarized in Table 4 and are conclusive that the material can indeed be reprocessed without significant material degradation. The $T_{g}$ of the reprocessed material is stable, as is the Young's modulus. Nevertheless, reprocessing does induce only some light decrease in the material performances as the tensile strength and elongation at break slightly decreases.

Table 4. Characterization of biobased PU, PU-FO-30XL reprocessed several times.

\begin{tabular}{|c|c|c|c|c|}
\hline PU System & $\begin{array}{c}\mathrm{DSC} \\
\mathrm{T}_{\mathrm{g}} \\
\left({ }^{\circ} \mathrm{C}\right) \\
\end{array}$ & $\begin{array}{c}\text { Young's Modulus } \\
\text { E } \\
(\mathrm{MPa})\end{array}$ & $\begin{array}{c}\text { Tensile Strength } \\
\sigma \\
(\mathrm{MPa}) \\
\end{array}$ & Elongation (\%) \\
\hline PU-FO-30XL & -51 & $0.57 \pm 0.09$ & $0.49 \pm 0.04$ & $107 \pm 9$ \\
\hline PU-FO-30XL-RP1 & -50 & $0.62 \pm 0.03$ & $0.47 \pm 0.04$ & $83 \pm 5$ \\
\hline PU-FO-30XL-RP2 & -50 & $0.58 \pm 0.02$ & $0.40 \pm 0.03$ & $74 \pm 6$ \\
\hline
\end{tabular}

As depicted in Figure 10a, self-healing was studied by cutting a dumbbell sample of PU-FO-30XL in half and exposing it to 1 hour at $120^{\circ} \mathrm{C}$ and 2 days at $60{ }^{\circ} \mathrm{C}$ and denoted PU-FO-30XL-HL1. By utilizing the thermo-reversibility of the DA bonds, the breaking and reforming of the crosslinks allows a severed dumbbell sample to be healed when exposed to such heating cycles. The initial heating at $120^{\circ} \mathrm{C}$ for 1 hour allows to break the crosslinks, thus enhancing network mobility. Consequently, the polymer chains can locally flow giving rise to adhesion to the two severed pieces. The final heating step at $60 \stackrel{\circ}{ } \mathrm{C}$ for 2 days allows the network to be reformed by the DA reaction. As seen Figure 10b, the healed materials show a novel integrity and recovery in terms of Young's modulus with around $0.5 \mathrm{MPa}$, a value equivalent to the initial material. Only at high elongation, a decrease of the performances is visible. This behavior is largely indicative that the thermoreversible DA crosslinking of PUs allows the material to have self-healing properties. 
a)

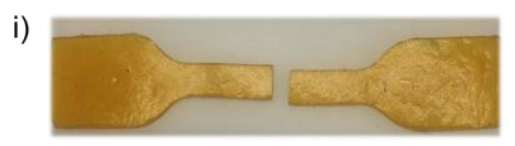

ii)

iii)

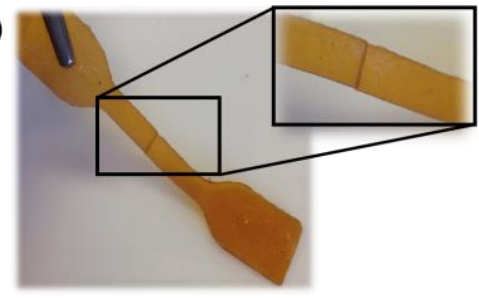

b)

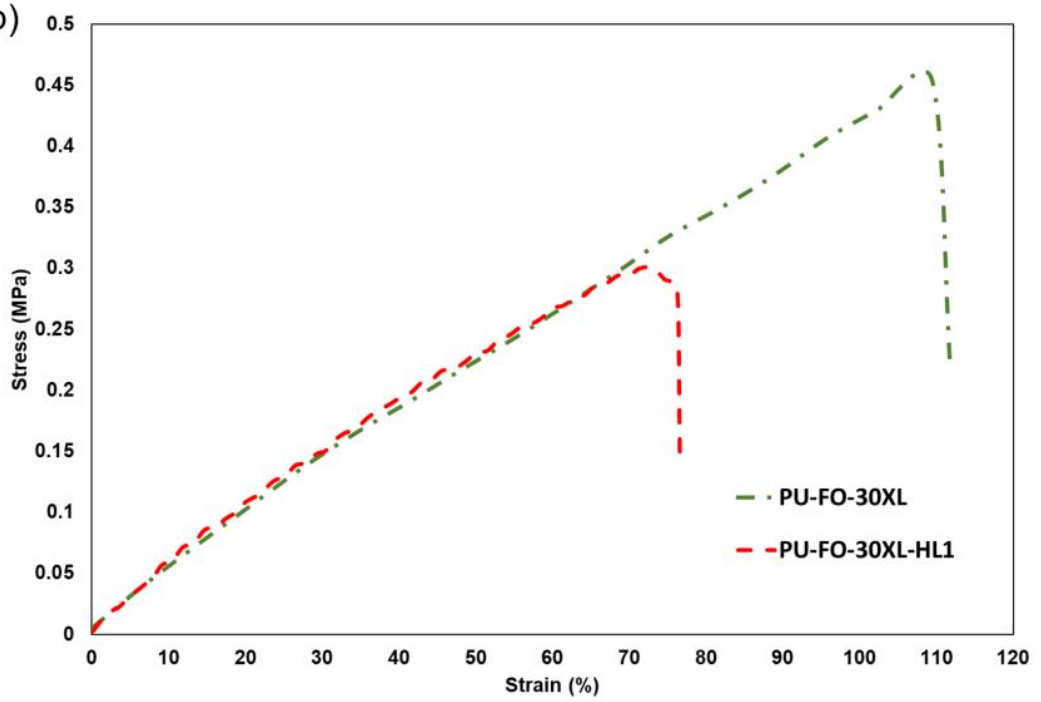

Figure 10. Self-healing evaluation. (a) (i) Photo of PU-FO-30XL dumbbell sample cut in half, (ii) healed dumbbell sample of PU-FO-30XL after heating1 hour at $120{ }^{\circ} \mathrm{C}$ and 2 days at $60{ }^{\circ} \mathrm{C}$, (iii) lifted healed dumbbell with zoom on healed section (b) Stress-strain curves of PU-FO-30XL and PU-FO-30XL-HL1

\section{Conclusion}

Thermo-reversible and self-healing crosslinked biobased systems based on urethane groups and clickable functions were successfully synthesized using vegetable oil derivatives and utilizing Diels-Alder reaction to control the design of their macromolecular architectures. A new biobased building block has been designed. The Furan Oligomer was developed from oleic acid in a sustainable way, largely in agreement with different green chemistry principles. As a general trend, crosslinked systems had characteristically higher $\mathrm{T}_{\mathrm{g}}$, insoluble ratio and enhanced stiffness and strength and lower swelling ratio when compared to their control PU counterparts. The crosslinked materials exhibit modular mechanical properties with respect to Furan Oligomer content. These biobased materials present a large range of behavior, from a typical thermoplastic elastomer-like material (least crosslinked material) to a thermoset (most crosslinked material). Reprocessing cycles were successfully performed and exhibited stable material properties. The systems also present self-healing properties. Dumbbell samples were cut in half, healed by joining the pieces together and exposing them to $120^{\circ} \mathrm{C}$, and cured at $60{ }^{\circ} \mathrm{C}$. Both parts were able to recombine and considerably mend the material. To this end, this work is a stepping-stone in developing vegetable oil-based architectures with integrated dynamicity for evolution of high-performance and advanced biobased materials. 
1 Future efforts will be dedicated to develop a greener chemistry with e.g. the reduction of the 2 solvent consumption and the use of more sustainable solvents. In the near future, similar 3 crosslinked vegetable oil based polyurethane formulation varying HS content can be studied for 4 material application such as adhesives and coatings thus providing exciting perspectives for a 5 greener future with advanced behavior to decrease the global impact of these materials, with a 6 controlled end of life. 


\section{Experimental Section}

2 Reagents and Materials

3 Octadec-9-enoic acid (OA) from sunflower oil was kindly supplied by ITERG. It is a technical grade 4 fatty acid with an acid value of $185 \mathrm{mg} \mathrm{KOH} / \mathrm{g}$. Furfuryl alcohol (FA, 98\%), 4-dimethylaminopyridine 5 (DMAP, 99\%), hydrogen peroxide $\left(\mathrm{H}_{2} \mathrm{O}_{2}, 30 \%\right.$ w/v aqueous solution), 2-chloro-4,4,5,5-tetramethyl6 1,3,2-dioxaphospholane (CL-TDP, 95\%), chromium (III) acetylacetonate (99.99\%), cholesterol (>99\%), dimethyl sulfoxide- $\mathrm{d}_{6}$ (DMSO, 100\%, 99.96\% atom D) were purchased from Sigma Aldrich; N,N'dicyclohexylcarboiimide (DCC, 99\%), polyether catalysis $\mathrm{HSbF}_{6}(65 \% \mathrm{w} / \mathrm{w}$ aqueous solution) were purchased from Alfa Aesar; hexamethylebne diisocyanate (HDI, 99\%), chloroform-d ( $\mathrm{CDCl}_{3}, 100 \%$, 99.96\% atom D) were purchased from Acros Organics; dichloromethane dried over molecular sieve (DCM, >99\%, stabilized with amylene), diethyl ether (stabilized with BHT) were purchased from Carlo Erba; toluene $(100 \%$, ) was purchased from VWR Chemicals; glacial acetic acid (GAA, >99\%), N,Ndimethylformamide (DMF, 99.8\%) was purchased from Fisher Scientific and amberlite IR-120 H from Fluka Chemicals. Biobased polyester polyol was purchased from Oleon is derived from dimeric fatty acids from rapeseed oil with purity greater than $98 \%$ and weight average molar mass $(\mathrm{Mw})$ around 3 $000 \mathrm{~g} / \mathrm{mol}$. Hydroxyl and acid values were 33 and $0.253 \mathrm{mg} / \mathrm{g} \mathrm{KOH}$, respectively. The poly(propylene oxide) based bismaleimide ( $\mathrm{DP}=3$ ) cross-linker was purchased from Specific Polymers (Castries, France). 2,3,4,5,6-pentafluorobenzaldehyde (PFB,98\%) was purchased from fluorochem.

Syntheses and Material Processing Esterification of Furan-2-ylmethanol and Octadec-9-enoic Acid from Sunflower Oil The esterification of Octadec-9-enoic acid (OA) was adapted from Vilela et al. and Rauf et al., ${ }^{[28,39]}$ for an esterification conducted under mild conditions. A solution included one molar equivalent of OA, $N, N$ '-dicyclohexylcarboiimide (DCC, $1.1 \mathrm{~mol}$ eq.), 4-dimethylaminopyridine (DMAP, $0.1 \mathrm{~mol}$ eq) in 25 $\mathrm{w} / \mathrm{v} \%$ of dried dichloromethane (DCM) was stirred magnetically for one hour in a two-necked round bottom flask at room temperature. Furfuryl Alcohol (FA, $1.1 \mathrm{~mol}$ eq) was then added dropwise through a dropping funnel. The reaction mixture was left stirring overnight at room temperature and under nitrogen. The $N, N^{\prime}$-dicyclohexylurea (DCU) formed during the reaction precipitated and was filtered off. The filtrate was washed twice with water, twice with $5 \%$ acetic acid solution and finally again with water until a neutral pH was attained. The organic phase was dried over anhydrous sodium sulphate. The solvent was evaporated under reduced pressure. The ester formed, Furan-2-ylmethyl-octadec-9enoate (FMO) was then further purified over a silica gel plug using petroleum ether/diethyl ether (95:5, $\mathrm{vol} / \mathrm{vol}$ ) as eluents to remove remnants of DCU. FMO was dried under vacuum overnight vacuum, at $50^{\circ} \mathrm{C}$. 
Furan-2-ylmethyl-octadec-9-enoate (FMO) - ${ }^{1} \mathrm{H}$ NMR $\left(400 \mathrm{MHz}, \mathrm{CDCl}_{3}, \delta(\mathrm{ppm})\right): 7.41(1 \mathrm{H}, \mathrm{dd}, 5-\mathrm{H}$ of 2-furan)), $6.39(1 \mathrm{H}, \mathrm{d}, 3-\mathrm{H}$ of 2-furan), $6.36(1 \mathrm{H}, \mathrm{dd}, 4-\mathrm{H}$ of 2-furan), $5.34(2 \mathrm{H}, \mathrm{m}, \mathrm{CH}=\mathrm{CH}), 5.06(2 \mathrm{H}$, $\left.\mathrm{s}, \mathrm{OCH}_{2}\right) 2.32(2 \mathrm{H}, \mathrm{t}, \mathrm{CH} 2 \mathrm{C}(=\mathrm{O})), 1.99\left(2 \mathrm{H}, \mathrm{m}, \mathrm{CH}=\mathrm{CHCH}_{2}\right) 1.62\left(2 \mathrm{H}, \mathrm{m}, \mathrm{CH}_{2} \mathrm{CH}_{2} \mathrm{C}(=\mathrm{O})\right)$, 1.37-1.18 $\left(2 \mathrm{H}, \mathrm{m}\right.$, aliphatic $\left.\mathrm{CH}_{2}\right), 0.88\left(3 \mathrm{H}, \mathrm{t}, \mathrm{CH}_{3}\right) .{ }^{13} \mathrm{C} \mathrm{NMR}\left(500 \mathrm{MHz}, \mathrm{CDCl}_{3}, \delta(\mathrm{ppm})\right): 1734(\mathrm{C}=\mathrm{O}), 150(\mathrm{C}-2$ of 2-furan), 143 (C-5 of 2-furan), $130(\mathrm{CH}=\mathrm{CH}), 130(\mathrm{CH}=\mathrm{CH}), 111$ (C-3 of 2-furan), 111 (C-4 of 2furan), $57.9\left(\mathrm{OCH}_{2}-2\right.$-furan), $34.2\left(\mathrm{CH}_{2}-\mathrm{C}(=\mathrm{O})\right)$, 31.9-22.7 (aliphatic $\left.\mathrm{CH}_{2}\right), 14.1\left(\mathrm{CH}_{3}\right)$

\section{Epoxidation of Furan-2-lymethyl-octadec-9-enoate}

The epoxidation of FMO was conducted by the in-situ formation of peracetic acid from glacial acetic acid and $\mathrm{H}_{2} \mathrm{O}_{2}$, and was adapted from Arbenz et al. In a two-necked round bottom flask, equipped with a magnetic stirrer and a dropping funnel, FMO (1 mol eq of unsaturations), amberlite IR-120 H ( $25 \mathrm{wt} \%$ of FMO), glacial acetic acid (0.2 mol eq) was inserted into the flask and dissolved in $12.5 \mathrm{wt} \%$ (m:v) of toluene. The solution was stirred to $70{ }^{\circ} \mathrm{C}$ and then $1.2 \mathrm{~mol}$ eq. of $\mathrm{H}_{2} \mathrm{O}_{2}$ was added dropwise. The mixture was stirred at $70^{\circ} \mathrm{C}$ for 7 hours. In comparison to current literature ${ }^{[32,40]}$, a lower acetic acid and $\mathrm{H}_{2} \mathrm{O}_{2}$ but increased toluene content is required to yield a high conversion of the alkene bond into an epoxy moiety, all the while minimizing the hydrolysis of the newly formed ester bond. The optimization trials of reactional components stoichiometry can be found in SI Table S1. Amberlite IR$120 \mathrm{H}$ was filtered off and the solution was washed with distilled water until a neutral $\mathrm{pH}$ was attained. The organic phase was dried with anhydrous sodium sulphate and then filtered. The solvent was evaporated under reduced pressure. Epoxidized FMO (EFMO) was dried under vacuum overnight, at $50{ }^{\circ} \mathrm{C}$. The reaction product, Furan-2-ylmethlyl 8-(3-octyloxiran-2-yl)octonoate (FMOO), was clear yellow oil.

Furan-2-ylmethlyl 8-(3-octyloxiran-2-yl)octonoate (FMOO) - ${ }^{1} \mathrm{H} \mathrm{NMR}\left(400 \mathrm{MHz}, \mathrm{CDCl}_{3}, \delta\right.$ (ppm)): $7.41(1 \mathrm{H}, \mathrm{dd}, 5-\mathrm{H}$ of 2-furan)), $6.39(1 \mathrm{H}, \mathrm{d}, 3-\mathrm{H}$ of 2 -furan), $6.36(1 \mathrm{H}, \mathrm{dd}, 4-\mathrm{H}$ of 2 -furan), $5.06(2 \mathrm{H}, \mathrm{s}$, $\left.\mathrm{OCH}_{2}\right), 2.90(2 \mathrm{H}, \mathrm{m}, \mathrm{CHOCH}), 2.32\left(2 \mathrm{H}, \mathrm{t}, \mathrm{CH}_{2} \mathrm{C}(=\mathrm{O})\right), 1.62\left(2 \mathrm{H}, \mathrm{m}, \mathrm{CH}_{2} \mathrm{CH}_{2} \mathrm{C}(=\mathrm{O})\right)$, 1.37-1.18 $(24 \mathrm{H}$, m, aliphatic $\left.\mathrm{CH}_{2}\right), 0.88\left(3 \mathrm{H}, \mathrm{t}, \mathrm{CH}_{3}\right) .{ }^{13} \mathrm{C}$ NMR $\left(500 \mathrm{MHz}, \mathrm{CDCl}_{3}, \delta(\mathrm{ppm})\right): 174(\mathrm{C}=\mathrm{O}), 150(\mathrm{C}-2$ of 2furan), 143 (C-5 of 2-furan), 111 (C-3 of 2-furan), 111 (C-4 of 2-furan), $57.9\left(\mathrm{OCH}_{2}-2\right.$-furan), 57.2 ( $\mathrm{HC}$ O-CH), $34.2\left(\mathrm{CH}_{2}-\mathrm{C}(=\mathrm{O})\right)$, 31.9-22.7 (aliphatic $\left.\mathrm{CH}_{2}\right), 14.1\left(\mathrm{CH}_{3}\right)$

\section{Oligomerization of Epoxidized Furan-2-lymethyl-octadec-9enoate (FMOO)}

For a molar equivalent of $\mathrm{FMOO}, \mathrm{H}_{2} \mathrm{O}(0.7 \mathrm{~mol}$ eq $)$ was added in a two-necked round bottom flask and stirred mechanically. A cationic initiator, $\mathrm{HSbF}_{6}(1.5 \mathrm{wt} \%$ of $\mathrm{FMOO})$ was added dropwise. The mixture was stirred at room temperature for $1 \mathrm{~h}$. The reaction was quenched by the addition of water and dissolved in diethyl ether. The organic solution was washed with a $5 \%$ sodium bicarbonate solution and distilled water until a neutral $\mathrm{pH}$ was attained. The solution was dried over anhydrous sodium 
sulfate, and filtered. The solvent was evaporated under reduced pressure and the oligomer was dried under vacuum overnight, at $50{ }^{\circ} \mathrm{C}$. The oligomerization resulted in an orange clear viscous oil.

Furan Oligomer: ${ }^{1} \mathrm{H} \mathrm{NMR}\left(400 \mathrm{MHz}, \mathrm{CDCl}_{3}, \delta(\mathrm{ppm})\right): 7.41(1 \mathrm{H}, \mathrm{dd}, 5-\mathrm{H}$ of 2-furan)), $6.39(1 \mathrm{H}, \mathrm{d}, 3-$ $\mathrm{H}$ of 2-furan), $6.36\left(1 \mathrm{H}, \mathrm{dd}, 4-\mathrm{H}\right.$ of 2-furan), $5.06\left(2 \mathrm{H}, \mathrm{s}, \mathrm{OCH}_{2}\right), 3.80$ - 2.82 (m, polyether backbone), $2.32\left(2 \mathrm{H}, \mathrm{t}, \mathrm{CH}_{2} \mathrm{C}(=\mathrm{O})\right), 1.62\left(2 \mathrm{H}, \mathrm{m}, \mathrm{CH}_{2} \mathrm{CH}_{2} \mathrm{C}(=\mathrm{O})\right), 1.37-1.18\left(24 \mathrm{H}, \mathrm{m}\right.$, aliphatic $\left.\mathrm{CH}_{2}\right), 0.88(3 \mathrm{H}, \mathrm{t}$, $\mathrm{CH}_{3} .{ }^{13} \mathrm{C}$ NMR $\left(500 \mathrm{MHz}, \mathrm{CDCl}_{3}, \delta(\mathrm{ppm})\right): 174(\mathrm{C}=\mathrm{O}), 150$ (C-2 of 2-furan), 143 (C-5 of 2-furan), 111 (C-3 of 2-furan), 111 (C-4 of 2-furan), 85.0-70.0 Polyether backbone(C-O-C), $57.9\left(\mathrm{OCH}_{2}\right.$-2-furan), 34.2 $\left(\mathrm{CH}_{2}-\mathrm{C}(=\mathrm{O})\right.$ ), 31.9-22.7 (aliphatic $\left.\mathrm{CH}_{2}\right), 14.1\left(\mathrm{CH}_{3}\right)$

\section{Model Reaction between FO and $\mathrm{N}$-methylmaleimide}

$200 \mathrm{mg}$ of FO ( $0.378 \mathrm{mmol}$ of furan) was dissolved in $2 \mathrm{~mL}$ of DMSO- $\mathrm{d}_{6}$ in a $10 \mathrm{~mL}$ round bottom flask. $\mathrm{N}$-methylmaleimide $(0.378 \mathrm{mmol}$ of maleimide) was added to obtain a furan to maleimide ratio of $1: 1$ $(\mathrm{mol} / \mathrm{mol})$. The solution was placed in an oil bath regulated to $65^{\circ} \mathrm{C}$ and samples of $200 \mu \mathrm{L}$ were taken at regular intervals over 5 days. The samples were further diluted to $650 \mu \mathrm{L}$ and analyzed by ${ }^{1} \mathrm{H}$ NMR to determine the reaction conversion and endo/exo ratio of the DA adducts.

\section{Diels-Alder and Retro-Diels-Alder Reaction between FO and a Bismaleimide}

FO and a PPO-based BMI were mixed together in a small flask at a 1:1 furan to maleimide ratio $(\mathrm{mol} / \mathrm{mol})$ and dissolved in DMSO at $40 \mathrm{wt} \%$ concentration. The sample was heated in an oven at 60 ${ }^{\circ} \mathrm{C}$ without stirring. Once gelation occurred (typically after 24 hours), samples were heated to $120 \stackrel{\circ}{ }{ }^{\circ}$ for 1 hour in an oven to perform the r-DA reaction and the mixture returned to a liquid state. The sample was underwent the same cycle one more time. After crosslinking in solution, the gel was washed with water and dried in an oven at $40{ }^{\circ} \mathrm{C}$ under vacuum. The gel was analyzed by FTIR compared to the initial mixture of $\mathrm{FO}$ and $\mathrm{BMI}$.

\section{Synthesis of Polyurethanes containing FO}

All glassware and reactants were previously dried. Four different kinds of polyurethanes films were prepared with varying amounts of FO $(0 \%, 10 \%, 20 \%$ and $30 \%$ of total the hydroxyl value was derived from the FO, for example for FO-20\%, $2.96 \mathrm{mmol} \mathrm{OH}$ from FO). Under nitrogen, in a three-necked round bottom flask, biobased rapeseed polyester polyol $(11.8 \mathrm{mmol} \mathrm{OH})$ and $\mathrm{FO}(2.96 \mathrm{mmol} \mathrm{OH}$ ) was added to hexamethylene di-isocyanate ( $\mathrm{HDI}, 15.5 \mathrm{mmol} \mathrm{NCO}$ ) and the mixture was mechanically stirred at $70^{\circ} \mathrm{C}$ for $3-4 \mathrm{~h}$. The ratio $-\mathrm{NCO} /-\mathrm{OH}$ functional groups were fixed to $1.05 \mathrm{in}$ all cases.

\section{Crosslinking of Polyurethanes containing of FO}

The polyurethane was dissolved in dry DMF. To this, BMI was added in a 1:1 furan to maleimide ratio (mol/mol). The reaction mixture was stirred at $70^{\circ} \mathrm{C}$ for $12 \mathrm{~h}$ to allow for the DA adducts to form. The 
solution was poured into a polyetrafluoroethylene mold and put into the oven to evaporate the solvent $\left(70{ }^{\circ} \mathrm{C}, 48 \mathrm{~h}\right.$ ). Solvent traces were removed placing material under vacuum at $70{ }^{\circ} \mathrm{C}$ for $24 \mathrm{~h}$.

\section{Material Reprocessing of Crosslinked Polyurethanes}

Polyurethane films are reprocessed by compression molded in tile mold $(10 \mathrm{~cm} \times 10 \mathrm{~cm} \times 1 \mathrm{~mm})$ at $150{ }^{\circ} \mathrm{C}$ in LabTech Scientific press hot press. First, the films were cut in several small pieces and placed in the center of the tile and left to undergo a 10 minutes preheating cycle to soften the material. This was followed by several venting steps and the material was pressed with a constant applied force of $16 \mathrm{MPa}$ between the two plates. The square materials were then cured at $60^{\circ} \mathrm{C}$ in the oven for 48 hours and post cured for 24 hours at room temperature.

\section{Study of the Self-Healing Behavior}

The macroscopic self-healing ability of material PU-FO30XL was determined by observing how a dumbbell-shaped sample cut in half healed. To accomplish this, a dumbbell-shaped sample was cut in half in the middle and subsequently healed by placing the halves in contact for 1 hour at $120{ }^{\circ} \mathrm{C}$, followed by $60 \stackrel{\circ}{\circ}$ overnight and $24 \mathrm{~h}$ at room temperature.

\section{$\underline{\text { Methods }}$}

\section{Acid Value}

Acid value (AV) was determined according to ISO 660. Approximately $0.1 \mathrm{~g}$ of OA was dissolved in 50 $\mathrm{mL}$ of a 50:50 ethanol and diethyl ether solution. One drop of phenolphthalein solution used an indicator was added to the solution. Then titration is performed with $0.1 \mathrm{M}$ potassium hydroxide $(\mathrm{KOH})$ aqueous solution. $\mathrm{AV}$ is express in $\mathrm{mg}$ of $\mathrm{KOH} . \mathrm{g}^{-1}$ according to Equation 2.

$$
A V=\frac{\left(V_{e q} * C\right) * 56.1}{W s}
$$

Where $V_{\text {eq }}(\mathrm{mL})$ is the titration equivalent volume, $\mathrm{C}\left(\mathrm{mol} . \mathrm{L}^{-1}\right)$ is the $\mathrm{KOH}$ solution concentration and $W_{s}(g)$ is the $O A$ weight.

\section{lodine Value}

lodine value (IV), known as the measure of the double bond content, was determined using the Wijs method. This result is expressed in $\mathrm{g}$ of iodine $\left(\mathrm{I}_{2}\right)$ per $100 \mathrm{~g}$ of sample. A $0.5 \mathrm{~g}$ sample was dissolved in $20 \mathrm{~mL}$ of 50:50 mixture of cyclohexane and glacial acetic acid. Then, $25 \mathrm{~mL}$ of the Wijs solution $(0.1 \mathrm{M})$ composed of iodine chloride in glacial acetic acid solution was added; the corresponding solution was stirred for $1 \mathrm{~h}$ in the dark. Then, $20 \mathrm{~mL}$ of a $10 \mathrm{wt} \%$ potassium iodide aqueous solution and $150 \mathrm{~mL}$ of water was added to quench the reaction. The solution was then titrated with a $0.1 \mathrm{M}$ 
sodium thiosulphate $\left(\mathrm{Na}_{2} \mathrm{~S}_{2} \mathrm{O}_{3}\right)$ solution using starch solution as indicator. IV in $\mathrm{I}_{2} \mathrm{~g} / 100 \mathrm{~g}$ was determinate according to Equation 3 :

$$
I V=\frac{\left(V_{\text {blank }}-V_{s}\right) * C * 126.9}{W S} * 100
$$

$\mathrm{V}_{\text {blank }}(\mathrm{mL})$ and $\mathrm{V}_{S}(\mathrm{~mL})$ are the volumes of $\mathrm{Na}_{2} \mathrm{~S}_{2} \mathrm{O}_{3}$ solution required for blank and sample titrations, respectively. $\mathrm{C}\left(\mathrm{mol} \mathrm{L}^{-1}\right)$ is the $\mathrm{Na}_{2} \mathrm{~S}_{2} \mathrm{O}_{3}$ solution concentration and $\mathrm{W}_{S}(\mathrm{~g})$ is the sample weight. It is important to note that Wijs method does not react with the conjugated double bonds of the furan ring.

\section{NMR Spectroscopies}

All NMR spectra were recorded on a Bruker Ascend ${ }^{\text {TM }} 400$ or $500 \mathrm{MHz}$ spectrometer. Sample were dissolved in deuterated chloroform $\left(\mathrm{CDCl}_{3}\right)$ or deuterated dimethyl sulfoxide (DMSO-d6) with concentrations varying between $8-10$ and $20-30 \mathrm{mg} / \mathrm{mL}$ for ${ }^{1} \mathrm{H}-\mathrm{NMR}$ and ${ }^{13} \mathrm{C}-\mathrm{NMR}$, respectively. The number of scans was set to 128 for ${ }^{1} \mathrm{H}-N M R$ and 2048 for ${ }^{13} \mathrm{C}-\mathrm{NMR}$. The calibration of ${ }^{1} \mathrm{H}$ - and ${ }^{13} \mathrm{C}$ NMR spectra was performed using the chloroform peak at 7.26 and $77.16 \mathrm{ppm}$, respectively and DMSO peak at 2.50.

${ }^{31} \mathrm{P}$ NMR analysis was performed on FO and polyester polyol samples phosphytilated with 2-chloro4,4,5,5-tetramethyl-1,3,2-dioxaphospholane. Cholesterol was used as an internal standard, as described in standard protocols. ${ }^{[35 a]} 128$ scans were recorded with a 15 s delay and a spectral width of 80 ppm (180-100 ppm).

For quantitative ${ }^{1} \mathrm{H}$ NMR analysis, about $20 \mathrm{mg}$ of FO were dissolved in $0.5 \mathrm{~mL}$ of DMSO- $\mathrm{d}_{6}$ before the addition of $100 \mathrm{~mL}$ of a standard solution of pentafluorobenzaldehyde in DMSO- $\mathrm{d}_{6}, 32$ scans were collected 10 s delay.

\section{Fourier Transform Infrared Spectroscopy (FTIR)} Infrared spectroscopy was performed using a Fourier transformed infrared spectrometer, Nicolet 380 used in reflection mode equipped with an ATR diamond module (FTIR-ATR). An atmospheric background was collected before each sample analysis (32 scans, resolution $4 \mathrm{~cm}^{-1}$ ).

\section{Mass Spectroscopy - MALDI-TOF}

Mass spectra were acquired on a time-of-flight mass spectrometer (MALDI-TOF-TOF Autoflex Speed LRF, Bruker Daltonics, Bremen, Germany) equipped with a nitrogen laser ( $\lambda=337 \mathrm{~nm})$. An external multi-point calibration was carried out before each measurement. Scan accumulation and data processing were performed with FlexAnalysis 3.0 software. 2.5-dihydroxybenzoic acid (DHB) was obtained from Sigma-Aldrich. Matrix solutions was freshly prepared: DHB was dissolved to saturation 
in a $\mathrm{H}_{2} \mathrm{O} / \mathrm{CH}_{3} \mathrm{CN} / \mathrm{HCOOH}(50 / 50,1 \%)$ solution. Typically, $0.5 \mu \mathrm{L}$ of a mixture containing the sample solution and the matrix (1/1) was deposited on the stainless-steel plate.

\section{Rheological Measurements}

Time required to form a gel between $\mathrm{FO}$ and $\mathrm{BMI}$ at $60^{\circ} \mathrm{C}$ (gelation time, $\mathrm{t}_{\mathrm{gel}}$ ) was determined by dynamic oscillatory rheology measurements performed on a a TA Instruments Discovery HR-3 using ETC parallel $25 \mathrm{~mm}$ plate geometry upper plate and $60 \mathrm{~mm}$ lower plate. The viscometer was equipped with a Peltier system for temperature control. The evolution of storage ( $\left.G^{\prime}\right)$ and loss ( $\left.G^{\prime \prime}\right)$ modulus was measured at $60^{\circ} \mathrm{C}$ at a constant shear strain (1\%) and at $1 \mathrm{~Hz}$. The gel point was considered as the time where the curves of storage and loss modulus crossover at a fixed temperature and frequency.

\section{Thermal Gravimetric Analysis (TGA)}

Thermogravimetric analysis (TGA) was performed using a TA Instrument Hi-Res TGA Q5000 at a heating rate of $10{ }^{\circ} \mathrm{C} / \mathrm{min}$ from room temperature to $700{ }^{\circ} \mathrm{C}$ under nitrogen atmosphere (flow rate 25 $\mathrm{mL} / \mathrm{min})$. Sample weighed between 1-3 mg.

\section{Differential Scanning Calorimetry (DSC)}

Differential scanning calorimetry (DSC) was performed using a TA Instrument Q200 under nitrogen flow (50 mL/min). Samples of 1-3 mg were sealed in standard aluminum pans. Depending on the information to be acquired, different heating runs were performed. For the qualitative studies on the DA adduct and r-DA, the FO and PPO-based BMI mixtures were heated up from $-30{ }^{\circ} \mathrm{C}$ to $175^{\circ} \mathrm{C}$ with a heating ramp of $2.5^{\circ} \mathrm{C} / \mathrm{min}$. The glass transition temperature $\left(\mathrm{T}_{\mathrm{g}}\right)$ of crosslinked materials were recorded using a single heating ramp, from $-80^{\circ} \mathrm{C}$ to $175^{\circ} \mathrm{C}$ at $10^{\circ} \mathrm{C} / \mathrm{min}$. The $T_{g}$ of the non-crosslinked materials were recorded using cyclic procedure involving a heating ramp from $-80^{\circ} \mathrm{C}$ to $175^{\circ} \mathrm{C}$ at 10 ${ }^{\circ} \mathrm{C} / \mathrm{min}$, followed by a cooling ramp down to $-80^{\circ} \mathrm{C}$ at $5^{\circ} \mathrm{C} / \mathrm{min}$ and finally a second heating to $175^{\circ} \mathrm{C}$ at $10^{\circ} \mathrm{C} / \mathrm{min}$. The temperature was kept constant for 2 minutes at the end of each temperature ramp.

\section{Uniaxial Tensile Tests}

Tensile properties of materials were determined with an Instron tensile testing machine (model 5567 $\mathrm{H}$, USA), at a rate of $20 \mathrm{~mm} / \mathrm{min}$, using dumbbell specimens (dimensions: $30 \times 5 \times 1 \mathrm{~mm}^{3}$ ). For each formulation at least five dumbbell samples were tested.

\section{Swelling Index and Gel Content Determination}

Swelling measurements of the polymer network were carried out in DMF. The swelling percentage was determined using the weight difference between dried and swollen samples. The sample (written mi and ranging from 10 to $20 \mathrm{mg}$ ) was immersed in $15 \mathrm{~mL}$ of solvent. After $24 \mathrm{~h}$, the sample was removed from the solution, the surfaces were dried superficially using a filter paper, and the weight was recorded 
1 (ms). Three repetitions were conducted for each material and each respective solvent. For each

2 sample, a swelling ratio (SR) was calculated according to the Equation 4:

$$
S R=\frac{m_{s}-m_{i}}{m_{i}} * 100(4)
$$

4 The sample was then dried in a vacuum oven at $40^{\circ} \mathrm{C}$ during 1 day. The resulting weight was recorded $5 \quad\left(m_{f}\right)$ and the insoluble fraction (IF) was calculated according to the Equation 5:

$$
I F=\frac{m_{f}}{m_{i}} * 100(5)
$$


Acknowledgements

The authors would like to thank BPI-France for the funding of Trans'Alg Project and the corresponding consortium. Iterg for kindly providing technical grade oleic acid. The authors would like to thank Dr. Antoine Duval for his input, the R\&D Team of Soprema (France) and Sophie Wendels for help with rheological measurements.

\section{References}

[1] J. T. Haponiuk, K. Formela, in Polyurethane Polymers (Eds.: S. Thomas, J. Datta, J. T. Haponiuk, A. Reghunadhan), Elsevier, Amsterdam, 2017, pp. 1-20.

[2] C. Carré, Y. Ecochard, S. Caillol, L. Averous, ChemSusChem 2019, 12.

[3] J. Akindoyo, M. Beg, S. Ghazali, M. Islam, N. Jeyaratnam, Y. Ar, Polyurethane types, synthesis and applications-a review, Vol. 6, 2016.

[4] G. Lligadas, J. C. Ronda, M. Galia, V. Cadiz, Mater. Today 2013, 16, 337-343.

[5] aM. A. R. Meier, J. O. Metzger, U. S. Schubert, Chemical Society Reviews 2007, 36, 1788-1802; bM. Desroches, M. Escouvois, R. Auvergne, S. Caillol, B. Boutevin, Polymer Reviews 2012, 52, 38-79.

[6] D. V. Palaskar, A. Boyer, E. Cloutet, J.-F. Le Meins, B. Gadenne, C. Alfos, C. Farcet, H. Cramail, Journal of Polymer Science Part A: Polymer Chemistry 2012, 50, 1766-1782.

[7] M. Desroches, S. Caillol, R. Auvergne, B. Boutevin, European Journal of Lipid Science and Technology 2012, $114,84-91$.

[8] aZ. S. Petrović, I. Cvetković, D. Hong, X. Wan, W. Zhang, T. Abraham, J. Malsam, Journal of Applied Polymer Science 2008, 108, 1184-1190; bY. J. Xu, Z. Petrovic, S. Das, G. L. Wilkes, Polymer 2008, 49, 4248-4258.

[9] M. Ionescu, Chemistry and Technology of Polyols for Polyurethanes., 2005.

[10] C. J. Kloxin, T. F. Scott, B. J. Adzima, C. N. Bowman, Macromolecules 2010, 43, 2643-2653.

[11] W. Denissen, J. M. Winne, F. E. Du Prez, Chemical Science 2016, 7, 30-38.

[12] D. Montarnal, M. Capelot, F. Tournilhac, L. Leibler, Science 2011, 334, 965-968.

[13] S. Dhers, G. Vantomme, L. Avérous, Green Chemistry 2019, 21, 1596-1601.

[14] A. Sanyal, Macromolecular Chemistry and Physics 2010, 211, 1417-1425.

[15] H. Otsuka, K. Aotani, Y. Higaki, Y. Amamoto, A. Takahara, Macromolecules 2007, 40, 1429-1434.

[16] aA. Gandini, A. J. F. Carvalho, E. Trovatti, R. K. Kramer, T. M. Lacerda, European Journal of Lipid Science and Technology 2018, 120, 1700091-n/a; bA. Gandini, T. M. Lacerda, A. J. F. Carvalho, E. Trovatti, Chemical Reviews 2016, 116, 16371669; cT. M. Lacerda, A. Gandini, Journal of Renewable Materials 2014, 2, 2-12; dA. Gandini, Progress in Polymer Science 2013, 38, 1-29.

[17] X. Chen, M. A. Dam, K. Ono, A. Mal, H. Shen, S. R. Nutt, K. Sheran, F. Wudl, Science 2002, 295, 1698-1702.

[18] R. C. Boutelle, B. H. Northrop, The Journal of Organic Chemistry 2011, 76, 7994-8002.

[19] aA. Duval, H. Lange, M. Lawoko, C. Crestini, Green Chemistry 2015, 17, 4991-5000; bP. Buono, A. Duval, L. Averous, Y. Habibi, Polymer 2017.

[20] A. Duval, G. Couture, S. Caillol, L. Averous, Acs Sustainable Chemistry \& Engineering 2017, 5, 1199-1207.

[21] C. García-Astrain, L. Avérous, Carbohydrate Polymers 2018, 190, 271-280.

[22] aC. García Astrain, R. Hernandez, O. Guaresti, L. Fruk, C. Mijangos, A. Eceiza, N. Gabilondo, Click Crosslinked Chitosan/Gold Nanocomposite Hydrogels, Vol. 301, 2016; bO. Guaresti, C. García-Astrain, R. H. Aguirresarobe, A. Eceiza, N. Gabilondo, Carbohydrate Polymers 2018, 183, 278-286; cO. Guaresti, C. García Astrain, L. Urbina, A. Eceiza, N. Gabilondo, Reversible swelling behaviour of Diels-Alder clicked chitosan hydrogels in response to pH changes, Vol. 13, 2018.

[23] K. González, C. García-Astrain, A. Santamaria-Echart, L. Ugarte, L. Avérous, A. Eceiza, N. Gabilondo, Carbohydrate Polymers 2018, 202, 372-381.

[24] Y. Heo, H. A. Sodano, Advanced Functional Materials 2014, 24, 5261-5268.

[25] aT. T. Truong, H. T. Nguyen, M. N. Phan, L.-T. T. Nguyen, Journal of Polymer Science Part A: Polymer Chemistry 2018, 56, 1806-1814; bT. T. Truong, S. H. Thai, H. T. Nguyen, D. T. T. Phung, L. T. Nguyen, H. Q. Pham, L.-T. T. Nguyen, Chemistry of Materials 2019, 31, 2347-2357; cB. Willocq, F. Khelifa, J. Brancart, G. Van Assche, P. Dubois, J. M. Raquez, RSC Advances 2017, 7, 48047-48053; dL. Irusta, M. J. Fernandez-Berridi, J. Aizpurua, Journal of Applied Polymer Science 2017, 134, 9; eE. Dolci, G. Michaud, F. Simon, B. Boutevin, S. Fouquay, S. Caillol, Polymer Chemistry 2015, 6, 7851-7861; fE. Dolci, V. Froidevaux, G. Michaud, F. Simon, R. Auvergne, S. Fouquay, S. Caillol, Journal of Applied Polymer Science 2017, 134, 11; gC. Lakatos, K. Czifrak, J. Karger-Kocsis, L. Daroczi, M. Zsuga, S. Keki, Journal of Applied Polymer Science 2016, 133; hP. F. Du, H. Y. Jia, Q. H. Chen, Z. Zheng, X. L. Wang, D. L. Chen, Journal of Applied Polymer Science 2016, 133; iG. Rivero, L.-T. T. Nguyen, X. K. D. Hillewaere, F. E. Du Prez, Macromolecules 2014, 47, 2010-2018. L. Gu, Q. Y. Wu, Journal of Applied Polymer Science 2018, 135, 46272.

J. F. Wilson, E. Y. X. Chen, ACS Sustainable Chemistry \& Engineering 2019, 7, 7035-7046.

C. Vilela, L. Cruciani, A. J. D. Silvestre, A. Gandini, Macromolecular Rapid Communications 2011, 32, 1319-1323. 
[29] A. Sengupta, T. Dey, M. Ghosh, J. Ghosh, S. J. J. o. T. I. o. E. S. E. Ghosh, 2012, 93, 31-36.

[30] K. Muthusamy, K. Lalitha, Y. S. Prasad, A. Thamizhanban, V. Sridharan, C. U. Maheswari, S. Nagarajan, 2018, 11, 24532463.

[31] S.-i. Shoda, H. Uyama, J.-i. Kadokawa, S. Kimura, S. Kobayashi, Chemical Reviews 2016, 116, 2307-2413.

[32] Z. S. Petrović, A. Zlatanić, C. C. Lava, S. Sinadinović-Fišer, European Journal of Lipid Science and Technology 2002, 104, 293-299.

[33] C. Kim, T. G. Traylor, C. L. Perrin, Journal of the American Chemical Society 1998, 120, 9513-9516.

[34] G. Lligadas, J. C. Ronda, M. Galià, U. Biermann, J. O. Metzger, Journal of Polymer Science Part A: Polymer Chemistry 2006, 44, 634-645.

[35] aA. Spyros, Journal of Applied Polymer Science 2002, 83, 1635-1642; bP. Korntner, I. Sumerskii, M. Bacher, T. Rosenau, A. Potthast, Holzforschung 2015, 69, 807-814.

[36] V. Froidevaux, M. Borne, E. Laborbe, R. Auvergne, A. Gandini, B. Boutevin, RSC Advances 2015, 5, 37742-37754.

[37] aB. J. Adzima, H. A. Aguirre, C. J. Kloxin, T. F. Scott, C. N. Bowman, Macromolecules 2008, 41, 9112-9117; bG. Scheltjens, M. M. Diaz, J. Brancart, G. Van Assche, B. Mele, A self-healing polymer network based on reversible covalent bonding, Vol. 73, 2013.

[38] S. Das, D. F. Cox, G. L. Wilkes, D. B. Klinedinst, I. Yilgor, E. Yilgor, F. L. Beyer, Journal of Macromolecular Science, Part B 2007, 46, 853-875.

[39] A. Rauf, H. Parveen, European Journal of Lipid Science and Technology 2004, 106, 97-100.

[40] A. Arbenz, R. Perrin, L. Avérous, Journal of Polymers and the Environment 2017, 26, 254-262. 